Journal of Engineering Sciences, Assiut University, Vol. 37, No. 5, pp. 1253-1273, September 2009.

\title{
A COMPARATIVE STUDY OF IDENTITY ELEMENTS IN TOURISTIC ARCHITECTURAL BUILDINGS WITH THE DISTINGUISHING FEATURES OF TRADITIONAL YEMENI BUILDINGS IN ALMUKALLA CITY
}

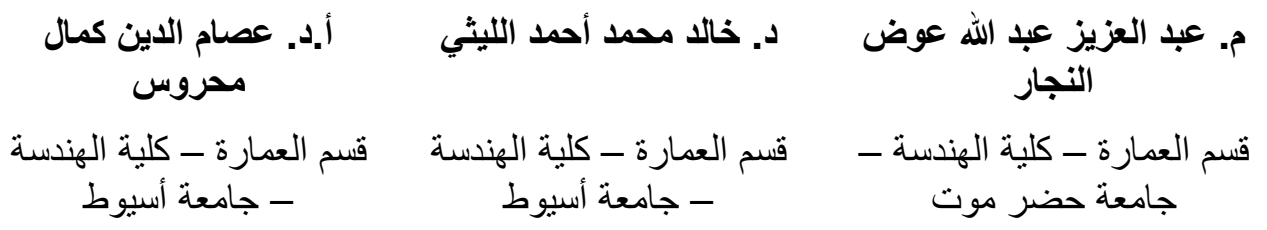

(Received June 30, 2009 Accepted July 18, 2009).

Architectural identity is a vital topic that raised many arguments recently, within maintaining the traditional architectural style of ancient cities. This paper discusses identity for the purpose of studying the absence of identity and characteristic style of traditional Yemeni architecture in contemporary tourist buildings, represented by hotels.

This paper aims to study the reasons and factors that led to the absence of architectural identity from tourist buildings in an attempt to root civilization values and features characterizing the architectural identity of traditional buildings in Yemeni cities. This was achieved by reviewing the distinguishing features of traditional Yemeni buildings in Almukalla city, as a tool to measure and compare the identity elements of contemporary Touristic Buildings in Almukalla city, with the items characterizing the architectural elements of traditional buildings.

This paper uses the analytical method, by presenting views of local architects (practicing and academic), by the questionnaire that treated in detail the points of identity, beside analyzing the results of a field survey for a selected sample of hotels in Mukalla to recognize the extent to which touristic buildings could maintain elements and items characterizing architectural identity of traditional buildings in the city.

This paper attempted to set some frameworks based on studying and evaluating the traits of local traditional architecture characteristic of Yemeni cities. They include functional spaces (varying from general to private use), and façade treatments (including building pattern, openings, ornaments, and building materials).

This paper is concluded with a number of results. The main points of results aim to maintain the characteristic style of traditional Yemeni architecture, and pay attention to the architecture of contemporary touristic buildings in Almukalla city. This is done by implementing the technical, and architectural Hadrami elements and create their own style; so that they achieve individuality and identity - characteristic of this type of buildings to express the style of their surrounding Yemeni environment. 


\section{مقارنة عناصر الهوية في عمارة المنشآت السياحية بالملامع المميزة للمباني اليمنية

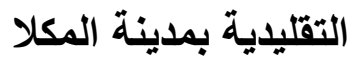

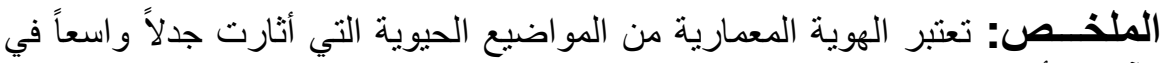

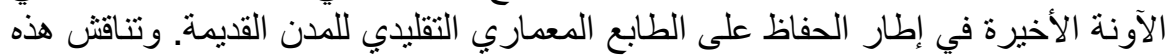

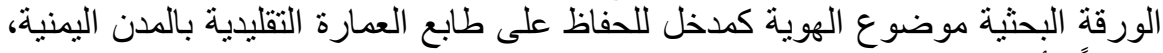

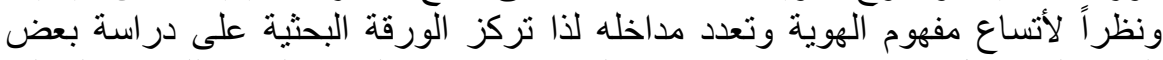

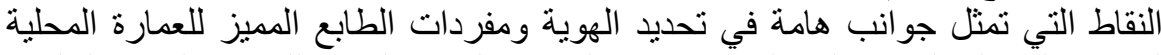

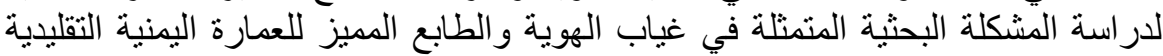

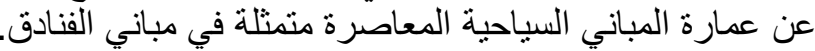

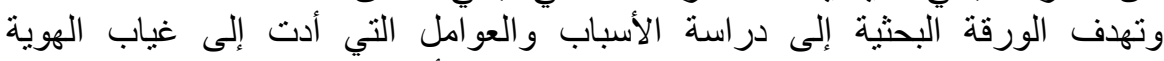

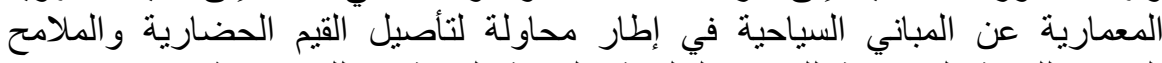

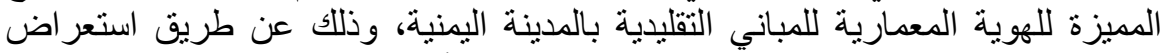

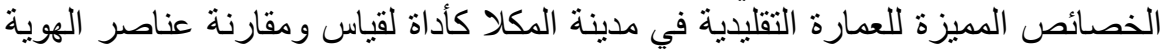

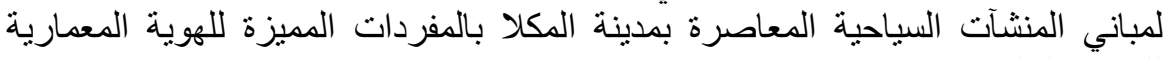
للمباني التقليدية. وقد اعتمدت الورقة البحثية على المنهج التحليلي من خلال عرض لأراء المعماريين

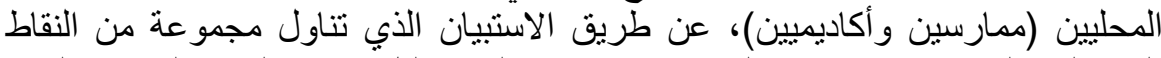

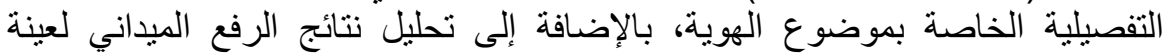

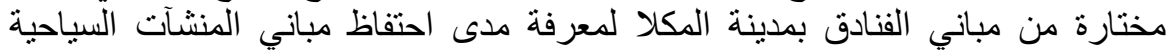
بالعناصر و المفردات المميزة للهوية المعمارية للمباني التقليدية بالمدينة.

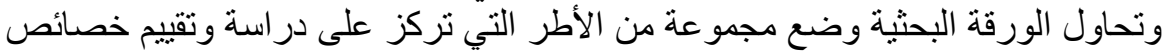

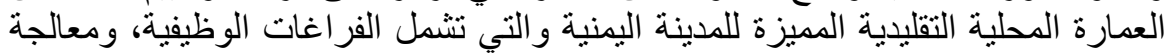

وتشكيل الو اجهات.

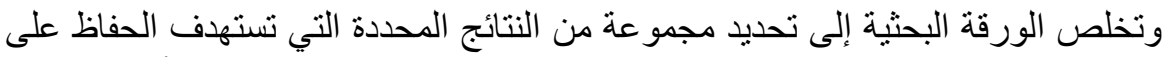

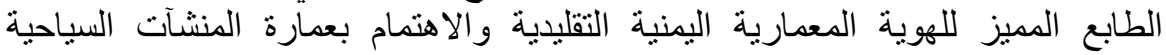

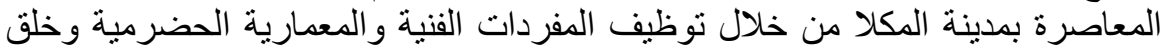

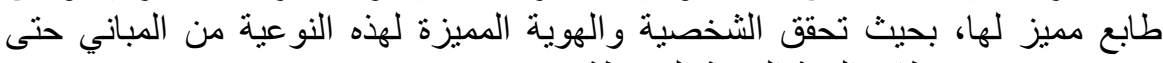
تخرج معبرة عن طابع البيئة اليمنية المحيطة لهئ.

الكلمات المفتاحية: الهوية المعمارية، الطابع المميز، المباني التقليدية اليمنية، مدينة المكلا، المنشآت السياحية، الفنادق

\section{1- المقدمة}

تحتل الهوية المعمارية مساحة كبيرة من فكر المهتمين بالعمـارة، بـل أنها تعتبر من القضـايا المعماريـة

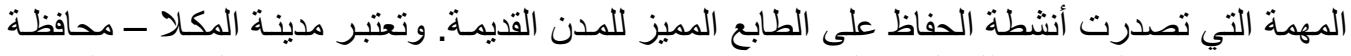

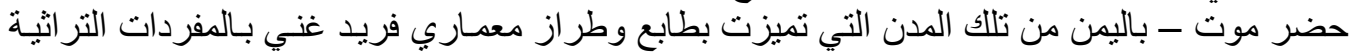

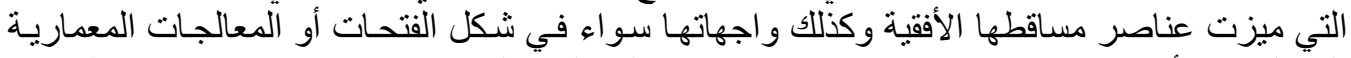

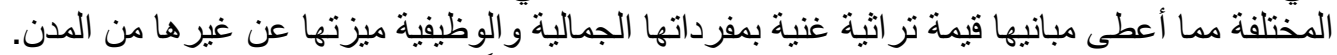

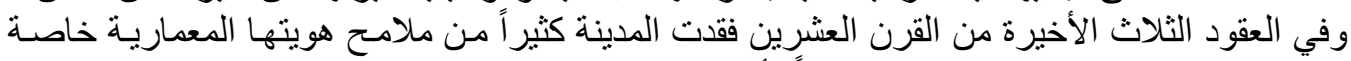

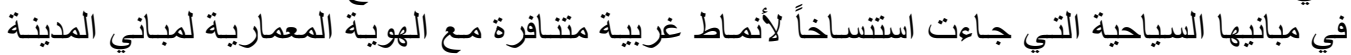
التقليدية مما أثر على الثكل العام والتجانس في الإدر الك البصري للطابع البيني المميز. 


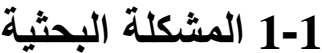

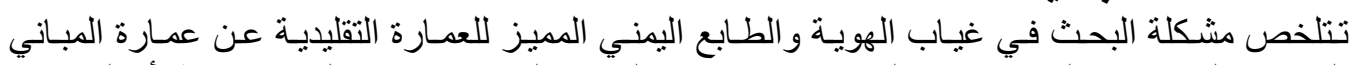

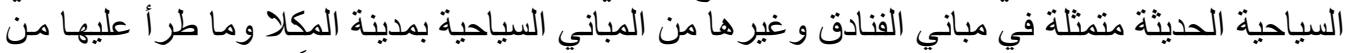

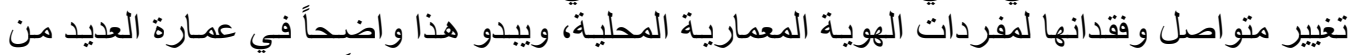

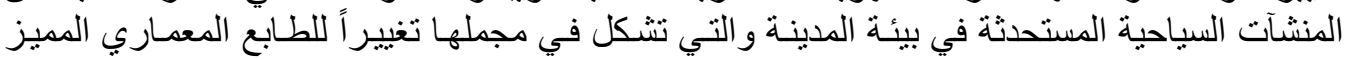

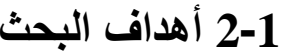

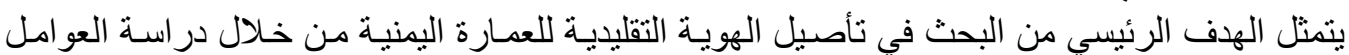

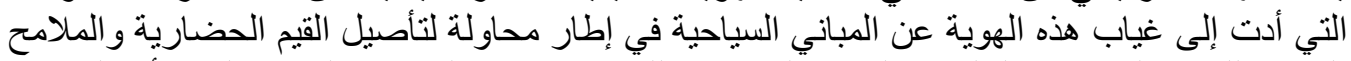

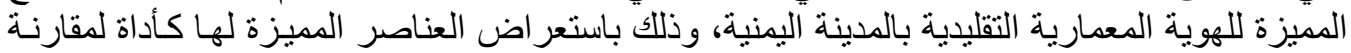
عناصر الهوية لمباني المنشآت السياحية المعاصرة بمدينة المكلا.

\section{3-1}

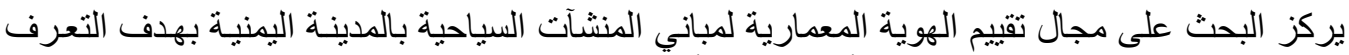

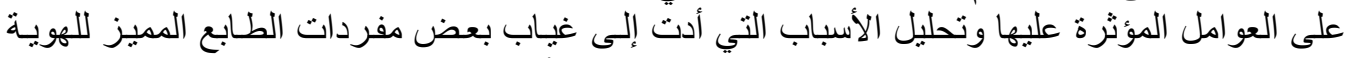
التقليدية، من خلال در اسة تحليلية لعينة مختارة من هذه المنشآت بمدينة المكلا.

4-1 البيانات والمطلومات

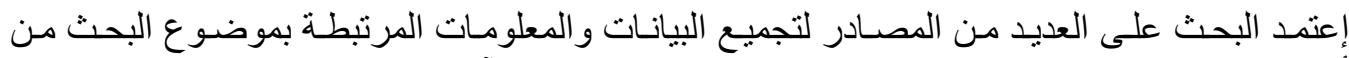

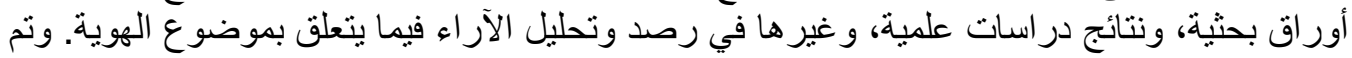

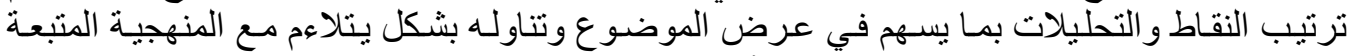
لتحليل مفردات الهوية المعمارية لمباني المنشآت السياحية بالمدينة اليمينية.

\section{5-1}

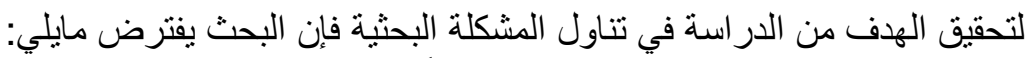

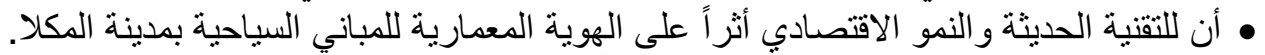
• أن للأطر اف المسئولة عن العملية السياحية دور أ في تأصيل الهوية للمباني السياحية بالية المدينة.

\section{6-1}

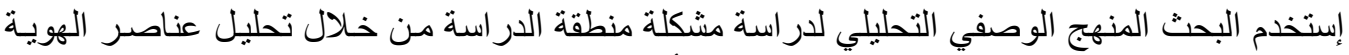

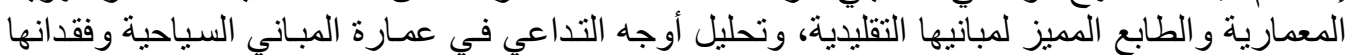

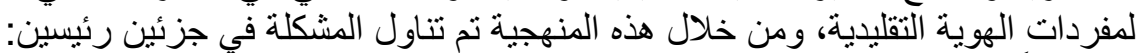

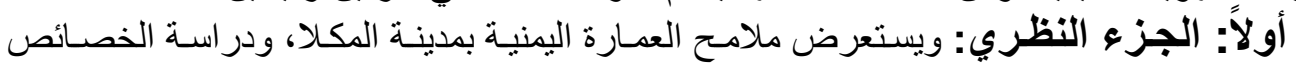

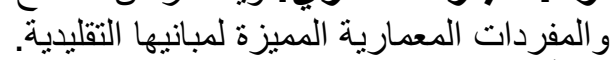

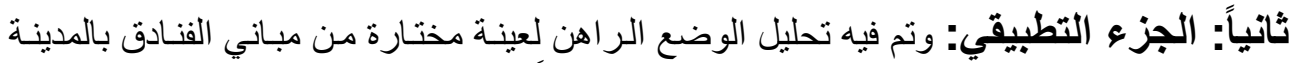

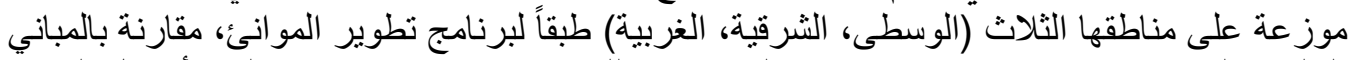

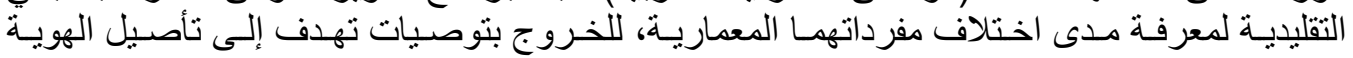

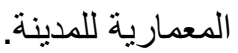




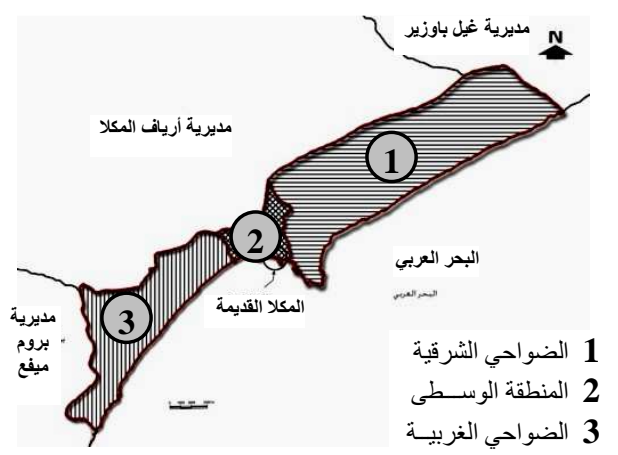

• المنطقة الوسطى وتعتبر قلب المدينة وبها أكثر المنشآت السياحية بالمدينة إذ إذبة تحتوي

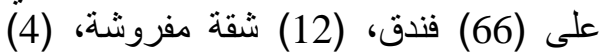
قصور أفراح، ومطعم سياحي.

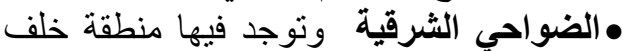

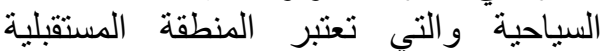

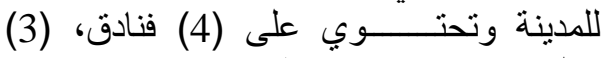
شاليهات سياحية، ومطعم سياحي، وحديقة ملاهي.

•الضواحي الغربية وتثتنمل هذه المنطقة على ثئل

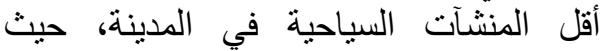
تحتوي على (4) فنادق، وصنالة أفراح.

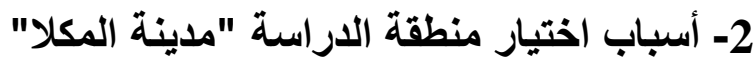

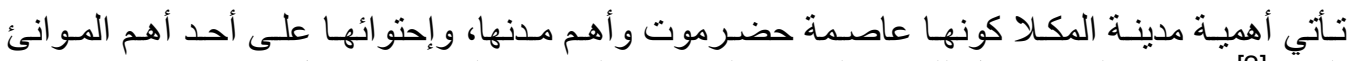

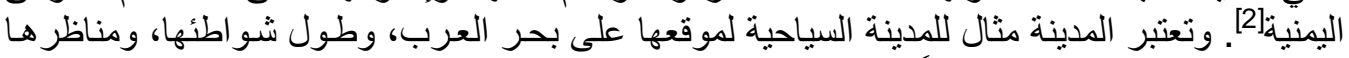

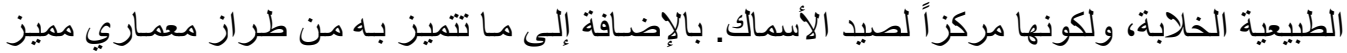

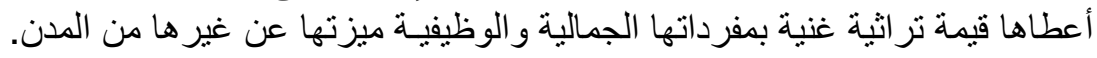

\section{3- الخصائص المميزة لهوية العمارة المحلية بمدينة المكلا}

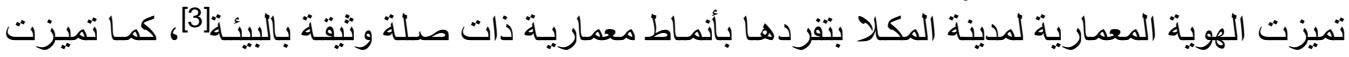

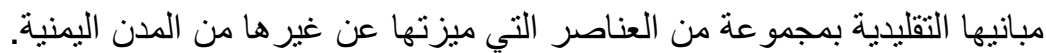

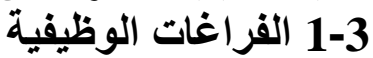

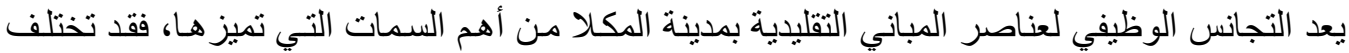

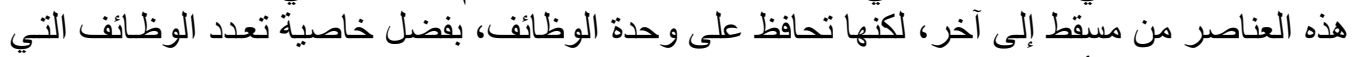

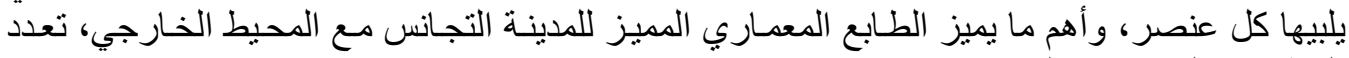
الوظائف، التدرج في الخصوصية:

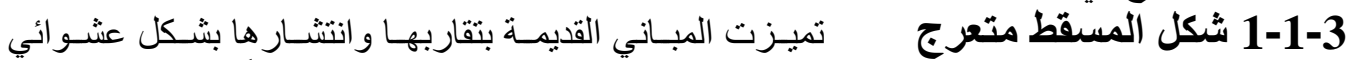

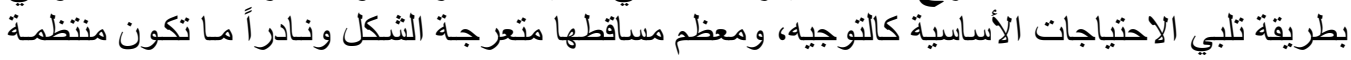
لتحقق التجانس مع المحيط الخارجي. 2-1-3 وجود أكثر من مدخل تميزت معظم المباني التقليدية بالمدينـة (العامـة والخاصـة) بوجود أكثر من مدخل بالإضافة إلى المدخل ملإنل الرئيسي. 3-1-3 تعدد الوظائف تلتعدد الوظائف بالمباني التقليديـة بالمدينة، وخصوصـاً البرجية منها، حيث يكون لكل دور وظيفة معينة.

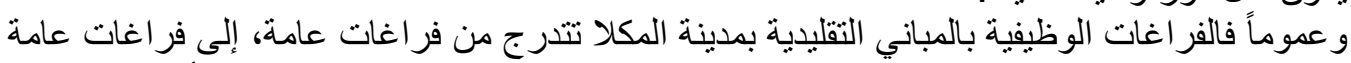

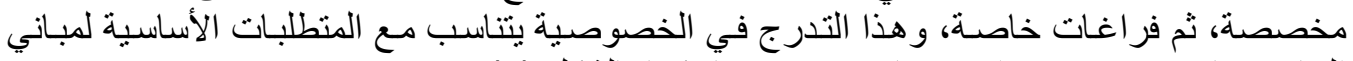
الفنادق بما يتلاءم مع مفردات و عناصر تصميمها، كما بالثكل (2). 


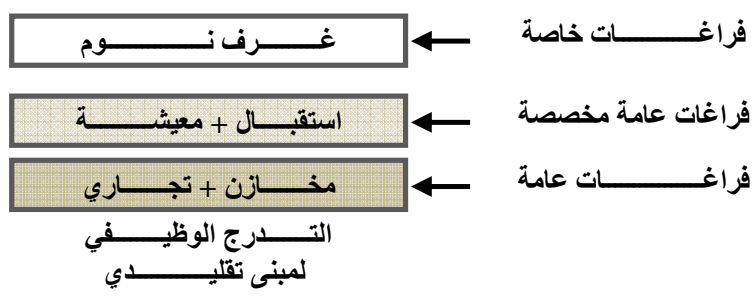

التدرج الوظيفي لمبنى تقليدي ومبنى سياحي يلائمه[1]

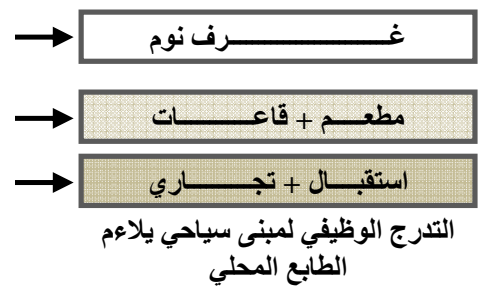

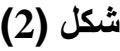

2-3 2-3 معالجة الواجهات

اختلفت المعالجات المعمارية لواجهات الوالئات المباني التقليدية في المدينة من حيث تتوع وتعدد القتحات، نمط البناء، نوع المواد المستخدمة:

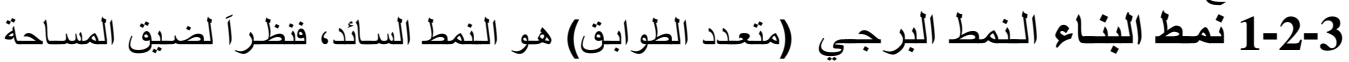

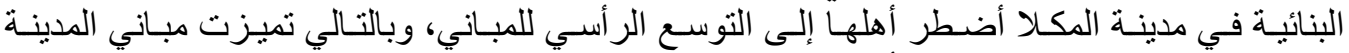

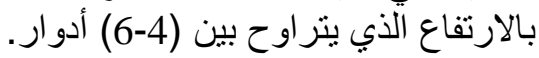

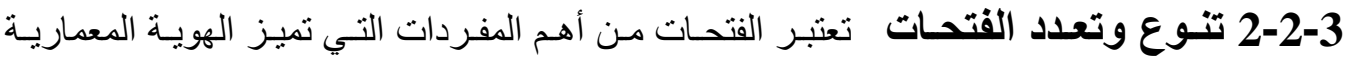

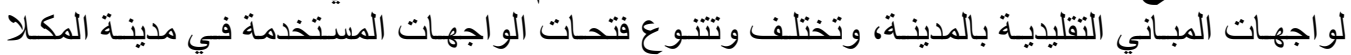
وأهمها:

- باب المدخل وهي من المفردات المعمارية الهامة التي لها دور كبير في تميز الواجهات واتهات الرئيسية

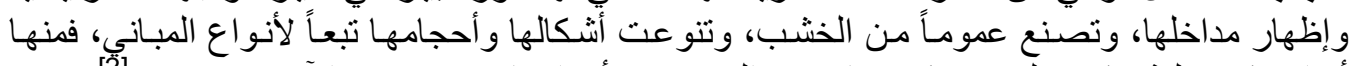

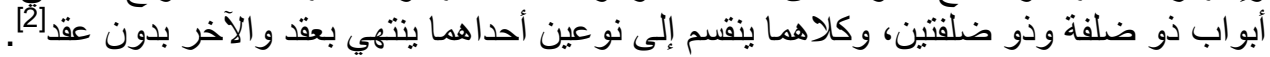

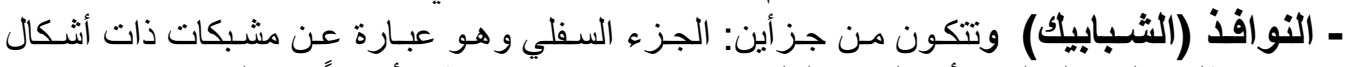

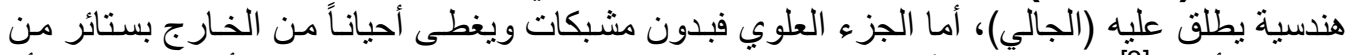

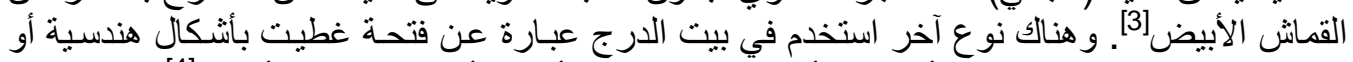

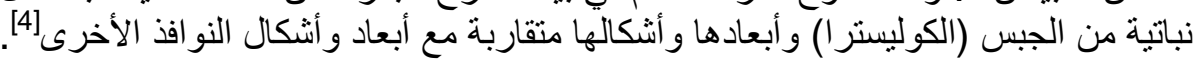

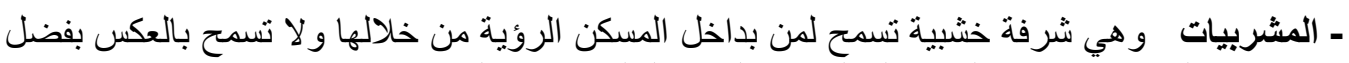

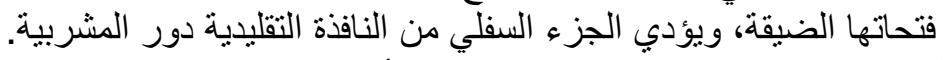

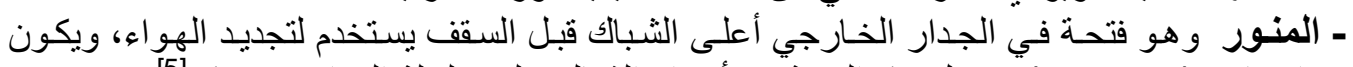

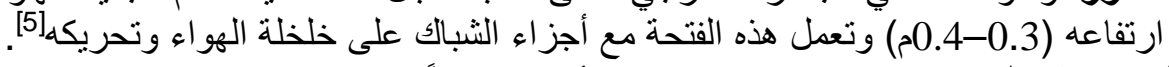

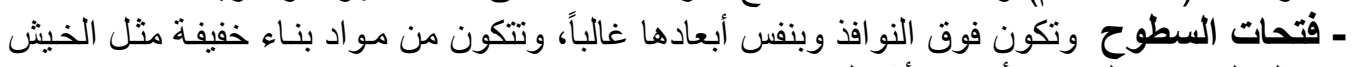

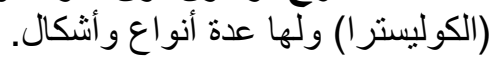

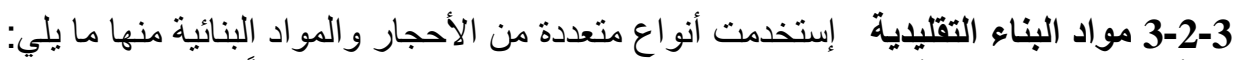

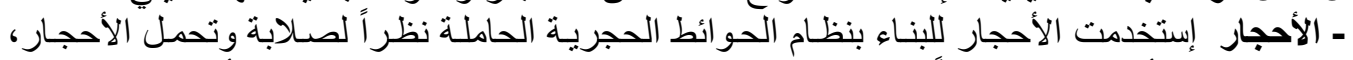

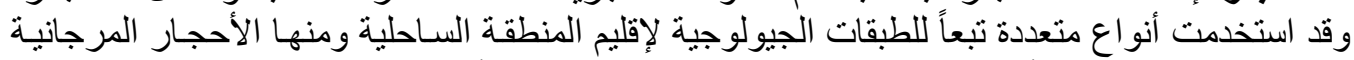

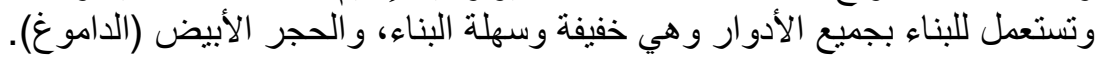



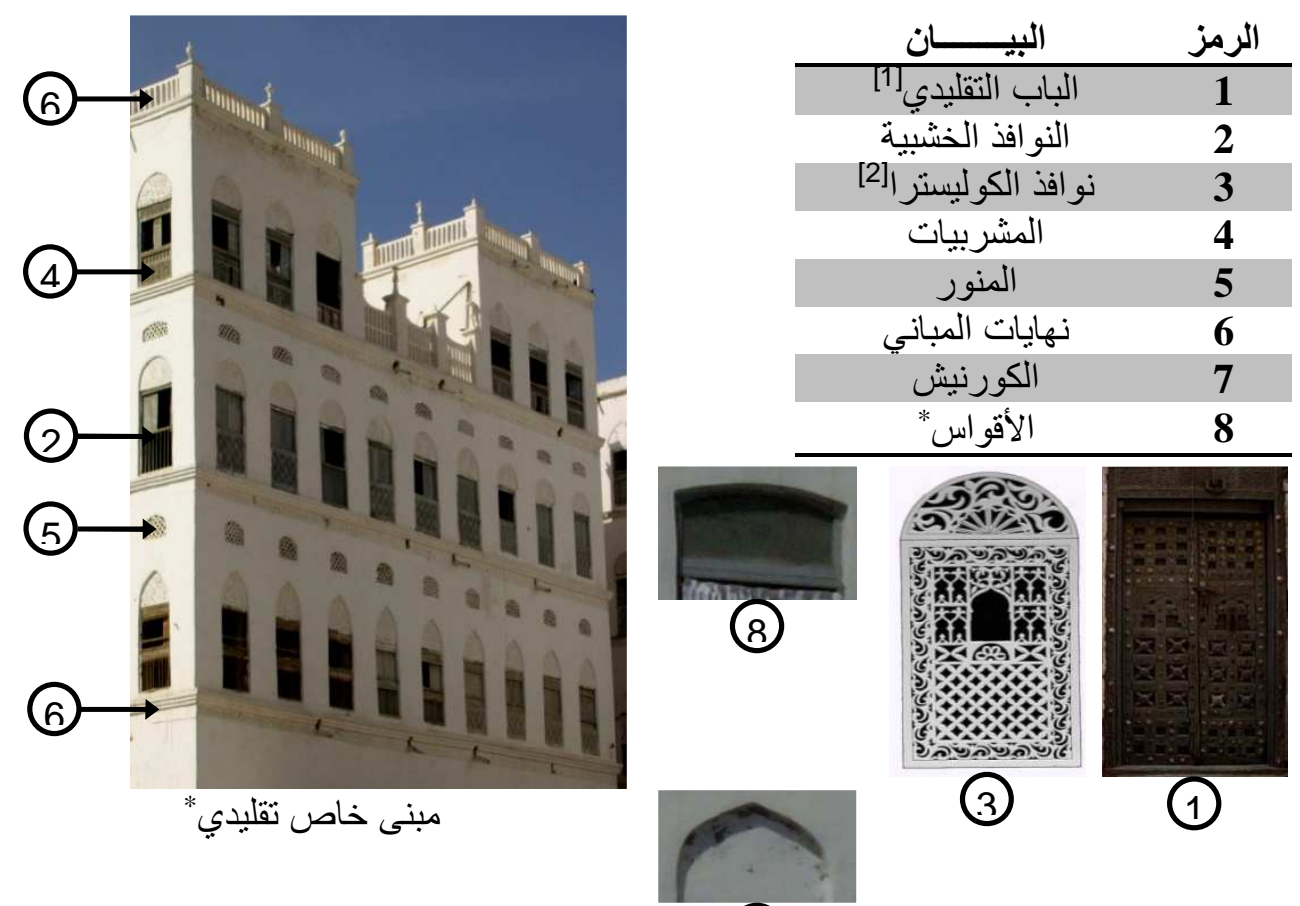

(8)

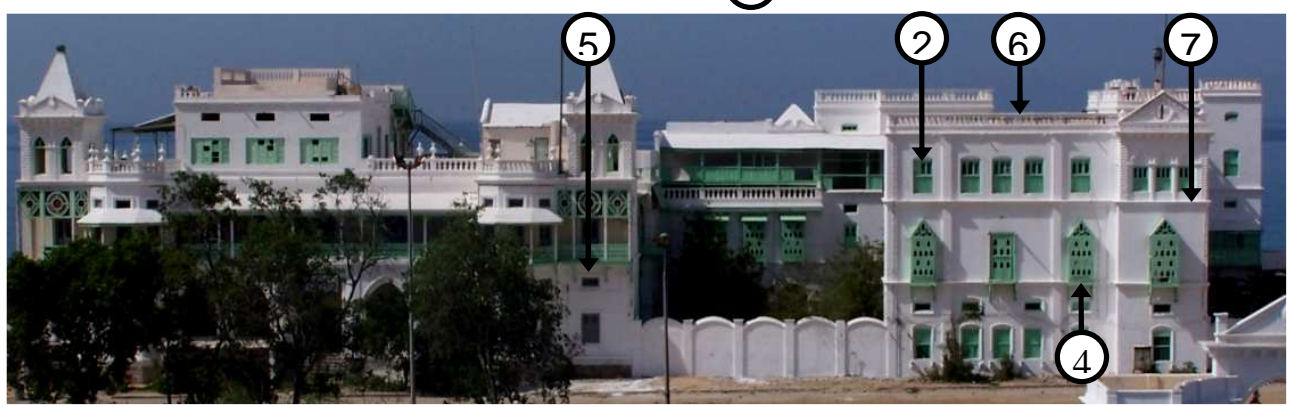

* مبنى تقليدي (قصر السلطان) شكل (3) تنوع وتعدد الفتحات في البيت التقليدي

ـ الطوب الطيني(المدر) و واستخدامه قليل بسبب موقع المدينة على الساحل.

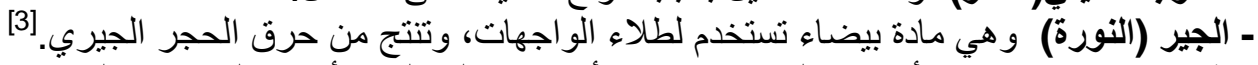

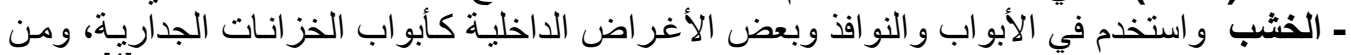

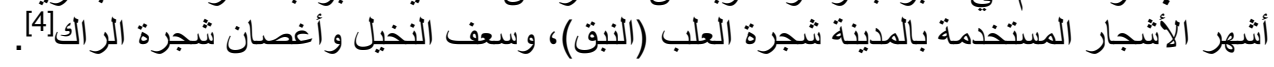

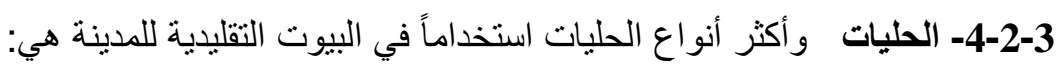




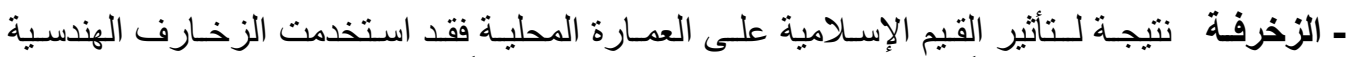
و النباتية فقط، وانتشرت كثثراً على الأبو اب و النو افذ وحولهما وأيضاً تحت الأفاريز (الكورنيش).

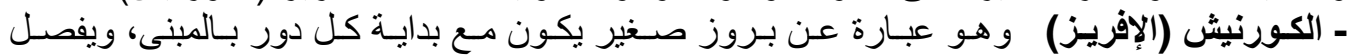

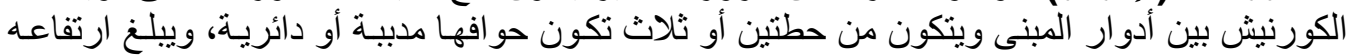

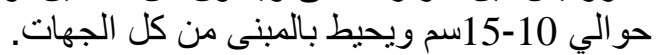

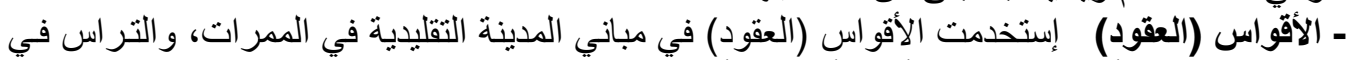

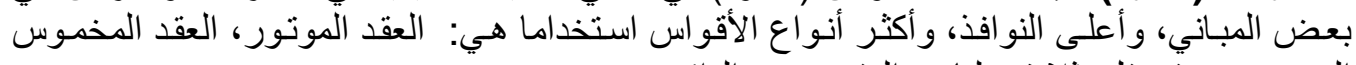

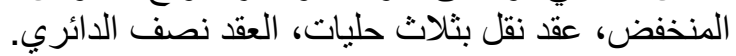

\section{4- تحليل الوضع الراهن للهوية المعمارية لمباني المنشآت السياحية بمدينة المكلا}

تركز الورقة البحثية على دراسـة وتحليل الوضـع الر اهن للهويـة المعماريـة لمبـاني المنشآت السياحية

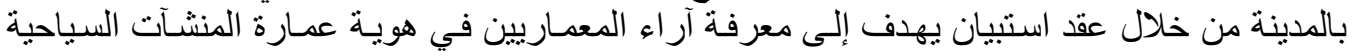

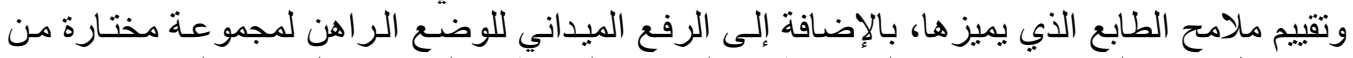

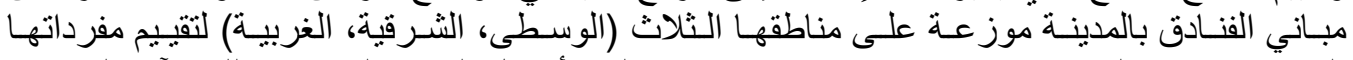

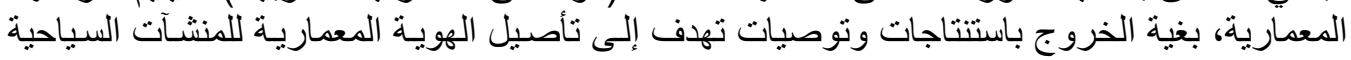

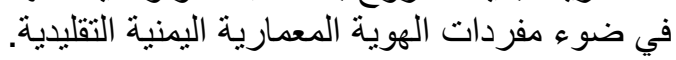

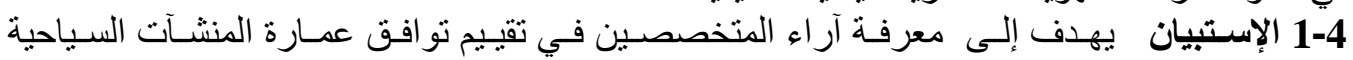

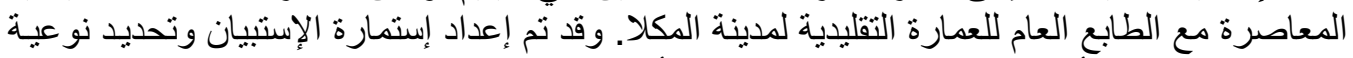

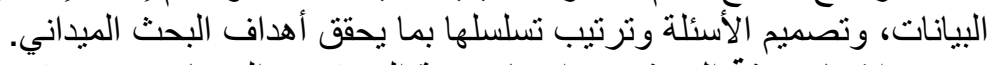

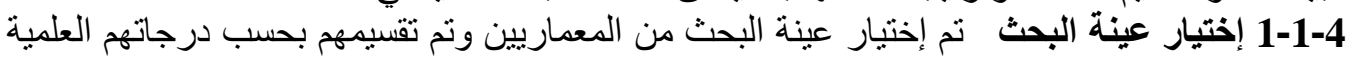

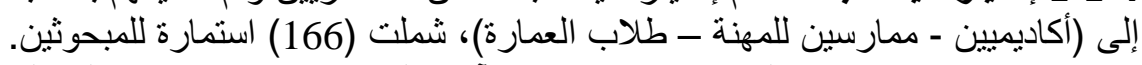

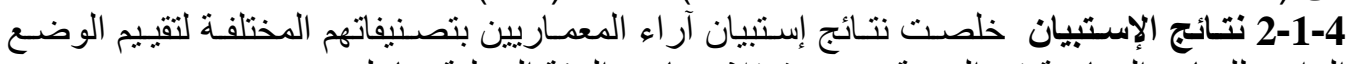

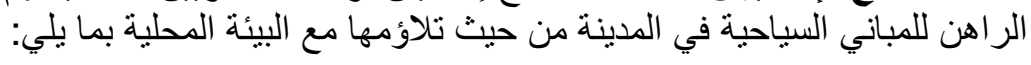

1- النسبة العظمى مـن المبحـوثين (72.3\%) أثــاروا إلـى أن الطـابع المعمـاري الحسالي للمنشـآت

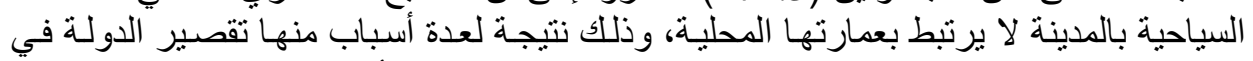

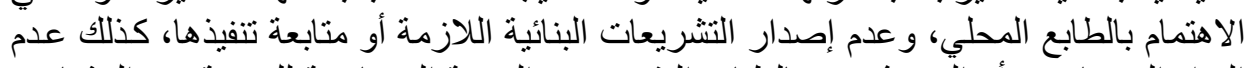

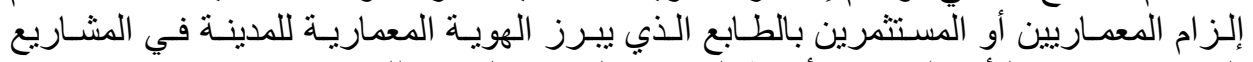

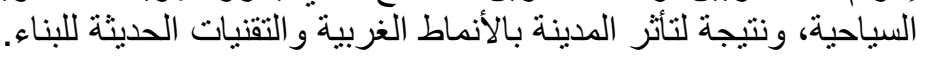

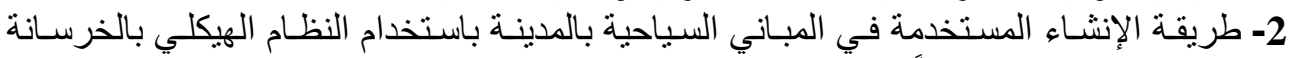

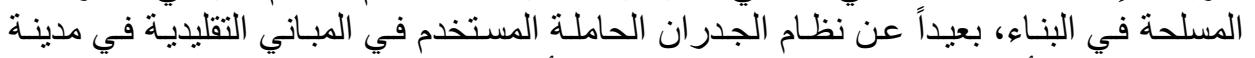

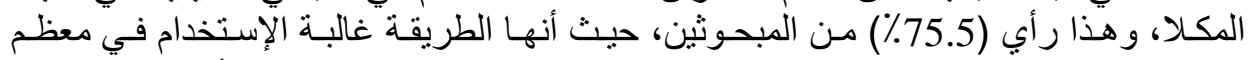

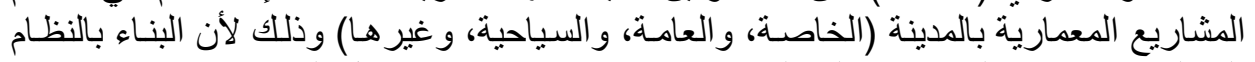

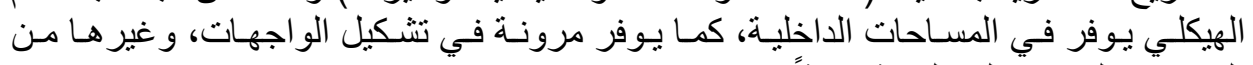

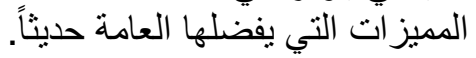

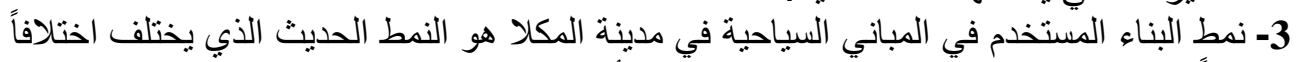

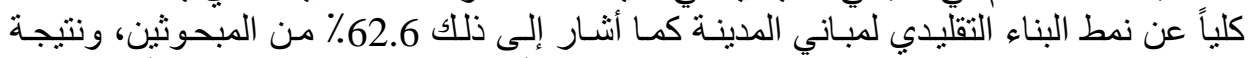

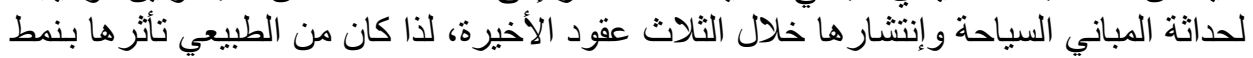

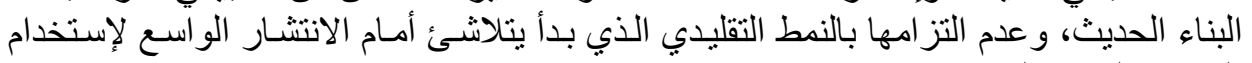

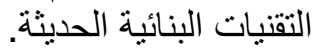




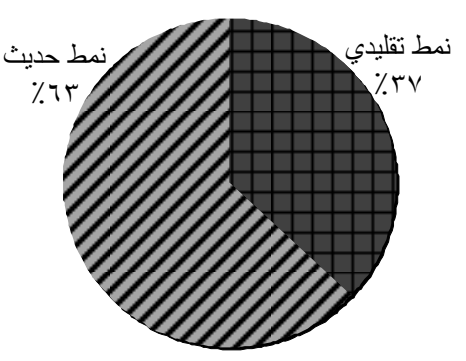

شكل (6) نمط البناء المستخدم في المباء المباني السياحية لمدينة المكلاء فئل

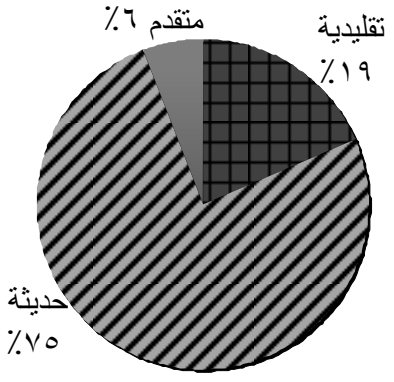

شكل (5) طريقة الإنشاء المستخدمة في المباني السياحية للمدينة

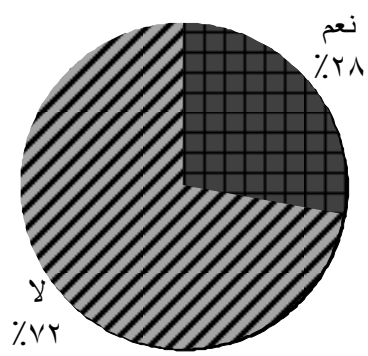

شكل (4) الطابع المعماري

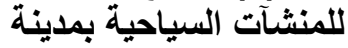
المكلا

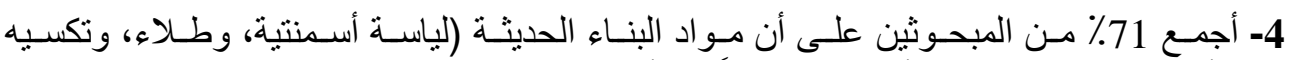

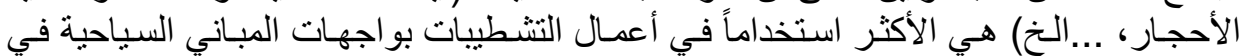

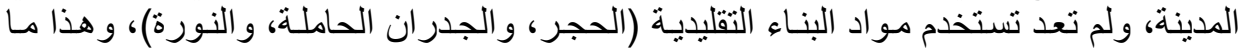

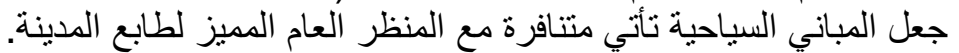

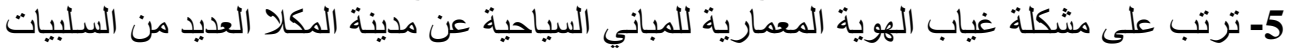

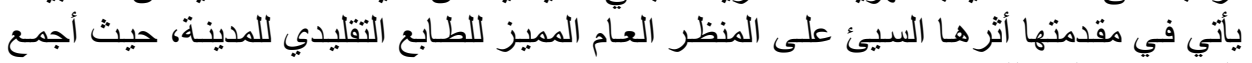

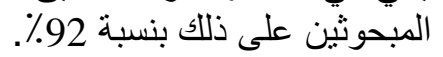

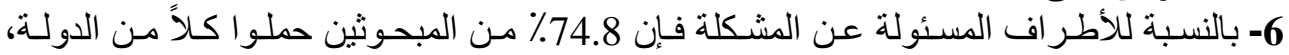

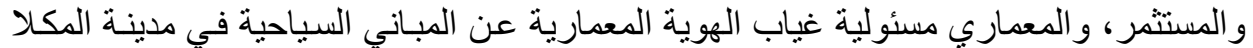

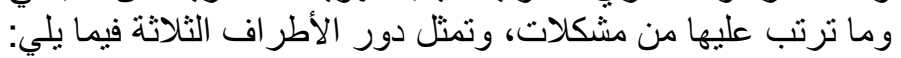

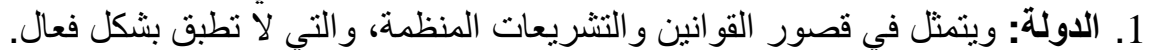

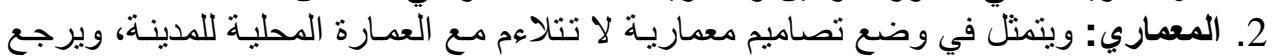

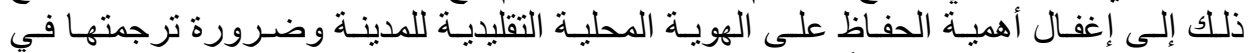

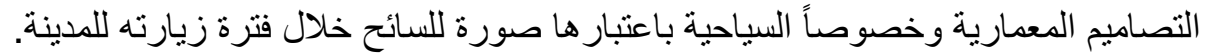

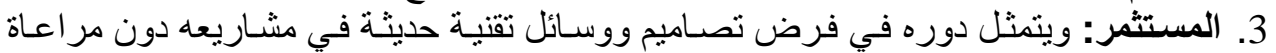
للطابع المحلي التقليدي للمدينة لإعتقاده بأن المباني الحديثة تجذب السياح بشكل أفضل.

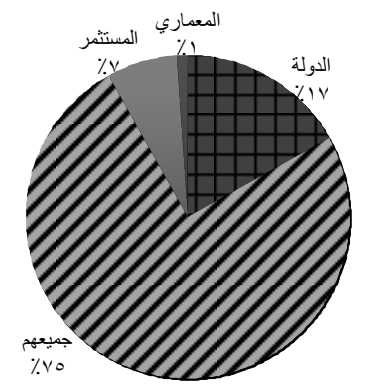

شكل (9) الأطراف المسئولة
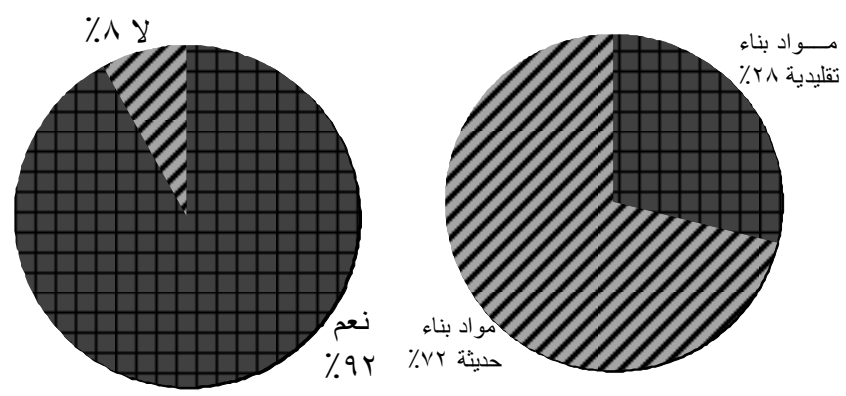

شكل (8) الآثار السلبية لالمشكية
شكل (7) مواد البناء المستخدمة 


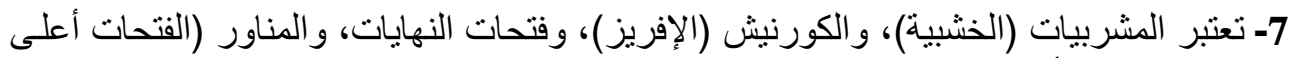

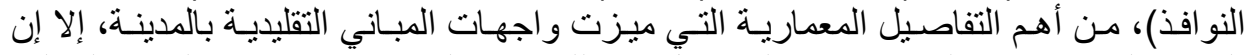

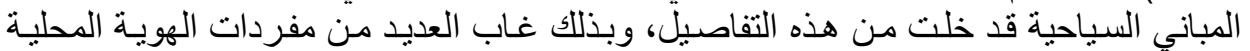

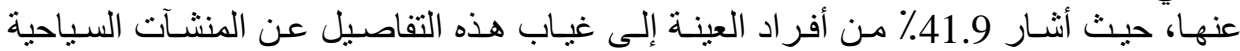

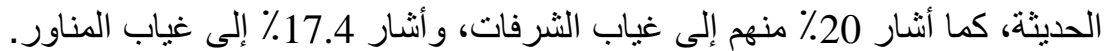

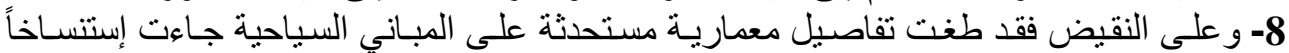

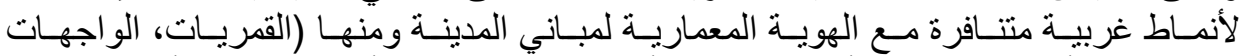

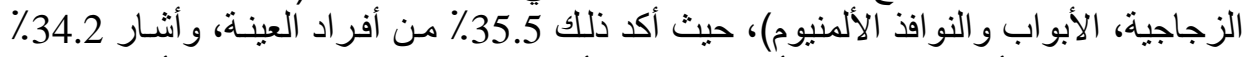

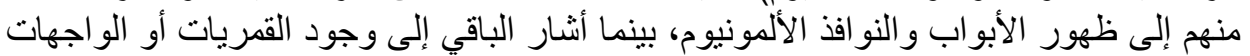

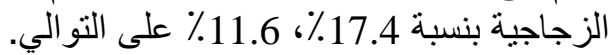

\section{2-4 تحليل الوضع الراهن للنماذج المختارة}

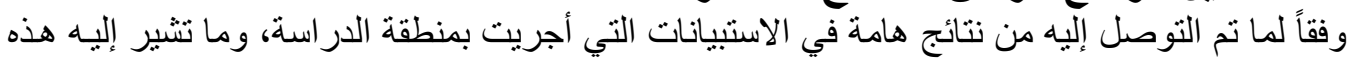

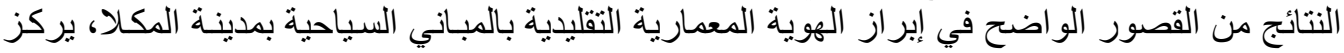

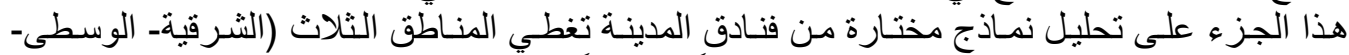
الغربية)، وسيتم تحليل الهوية المعمارية لها وظلية ونيفياً وتشكيلياً.

\section{1-2-4 فندق هوليدي ان مكلا}

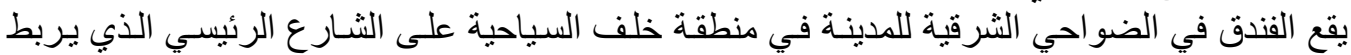

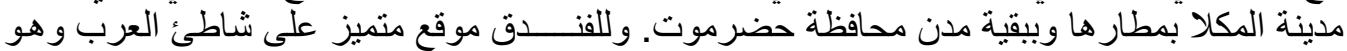

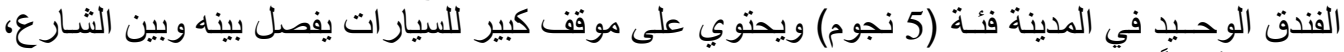

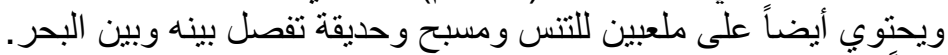

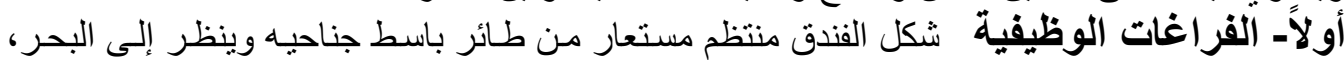

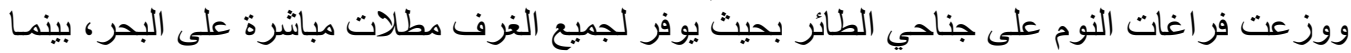

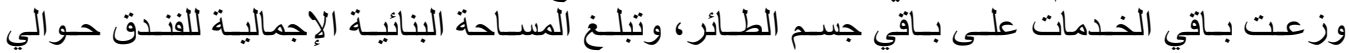
(299.5) موز عة على بدروم وخمسة طو ابق، كما هو مبين بشكل (10).

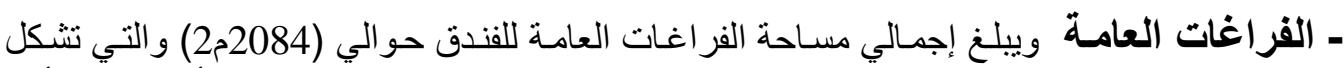

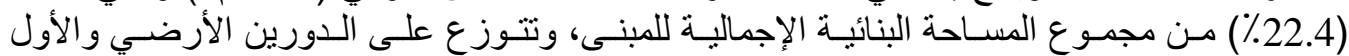

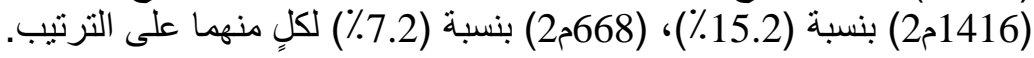

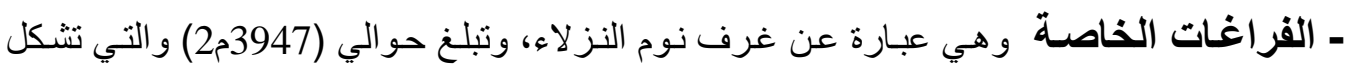

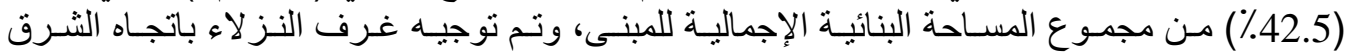

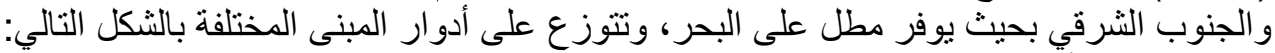

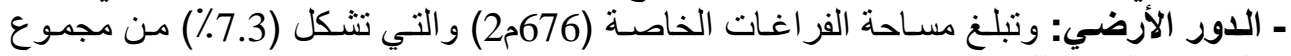

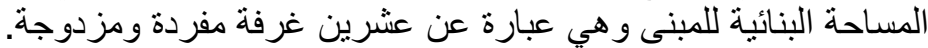

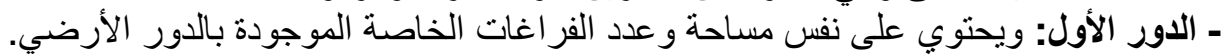

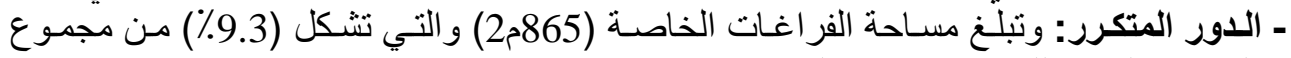
المساحة البنائية للمبنى وتثتوزع على عشرين غرفة نوم مفردة ومزدوجة، ولنئ وجناحي إقامة. 


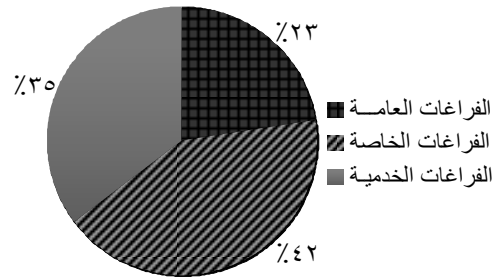

توزيع الفراغات الوظيفية لفندق هوليدي ان مكلا

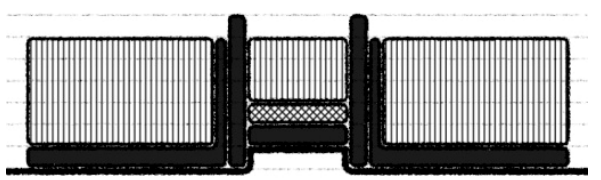

مقطع A-A مقع

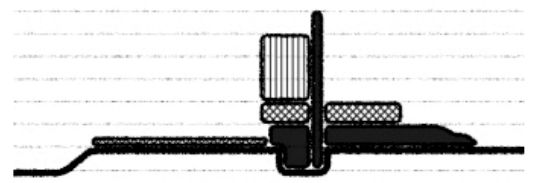

مقطع B-B

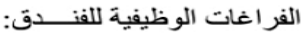

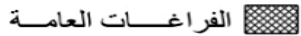

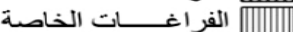

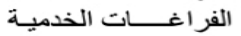

(الخدمات و عناصر الحركة الخمة )
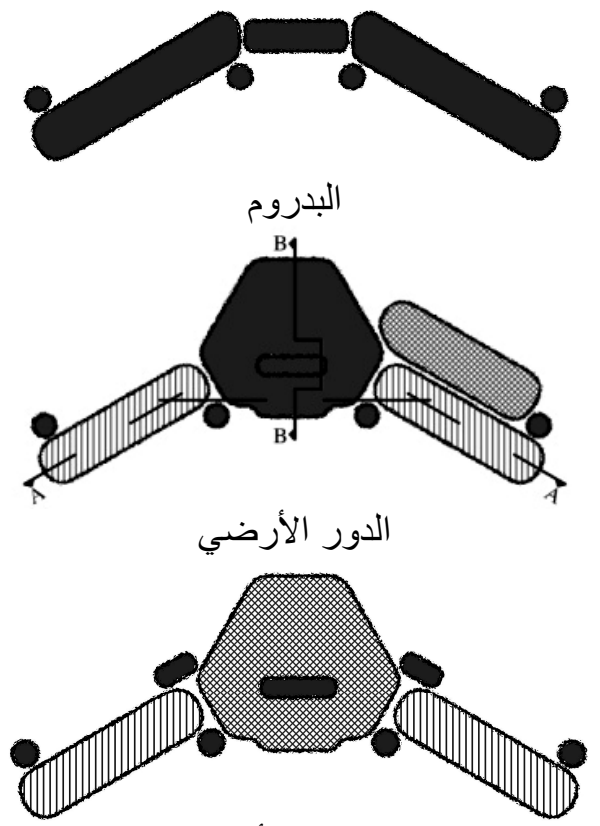

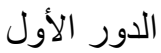

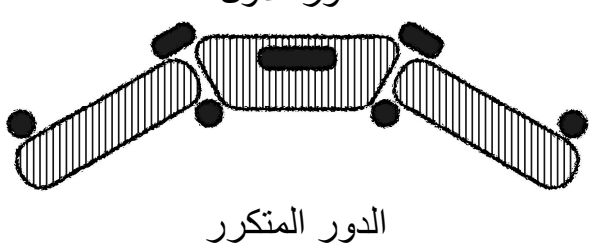

شكل (10) تحليل الفراغات الوظيفية لفندق هوليدي ان مكلا]1]

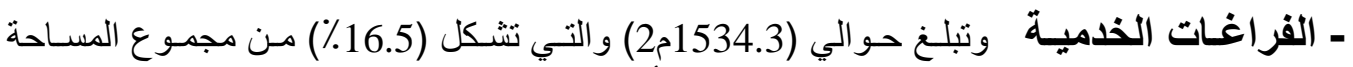

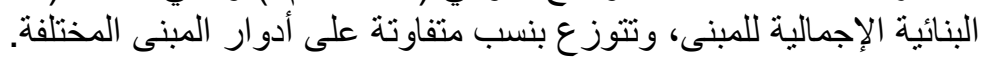

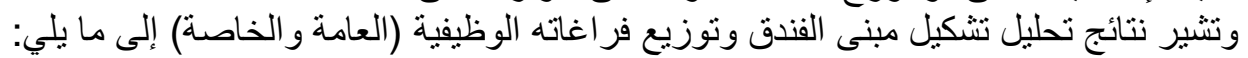

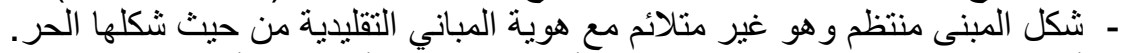

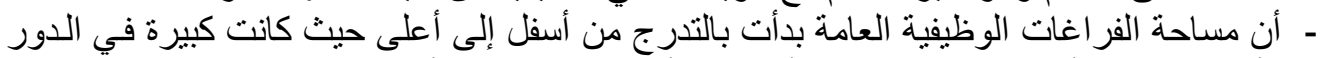

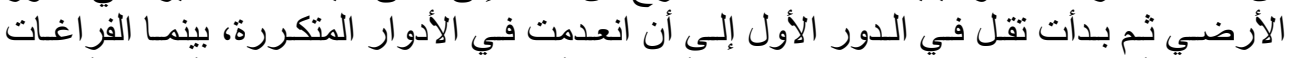

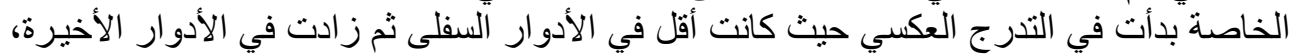

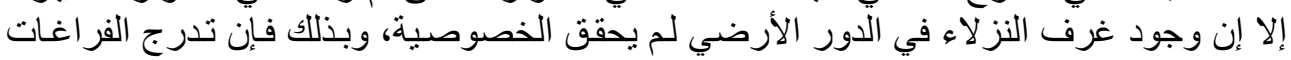

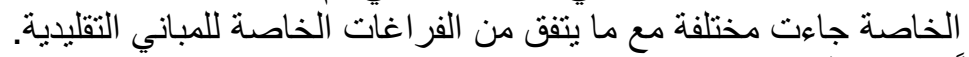

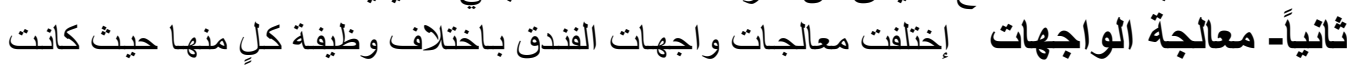

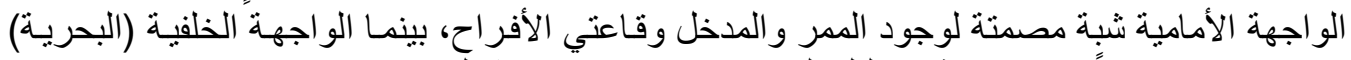
جاءت عكسها تماماً، وتم دراسة وتحليلة لوجيل الو اجهات كما هو مبين بشكل (11) من حيث: 


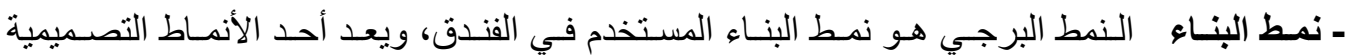
المستخدمة في المدينة، ويتلاءم هذا النمط مع نمط البناء المستخدم في المباني التقليدية بالمدينة. ـ تنوع وتعدد الفتحات تتوعت واختلفت الفتحات المستخدمة في واجهات الفندق تبعاً لوظائف كلٍ منها، الفهاء

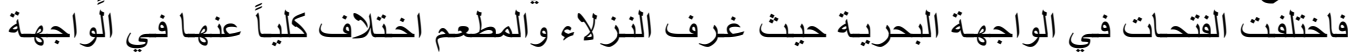

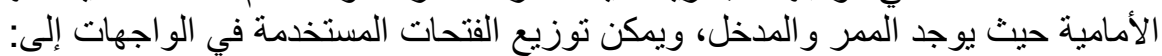

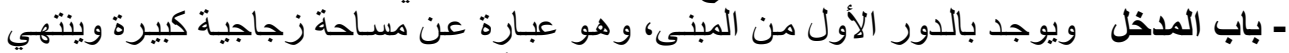

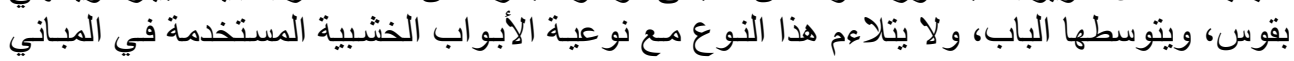

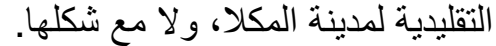

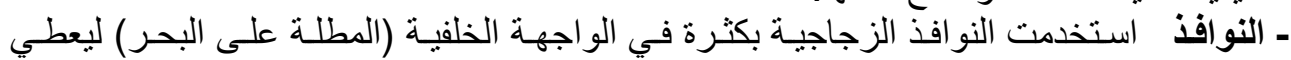

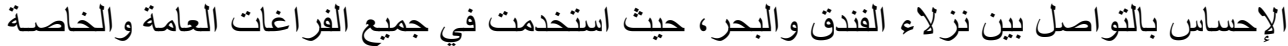

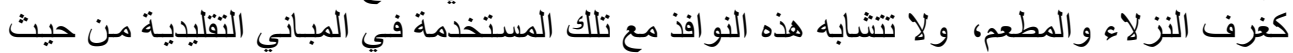

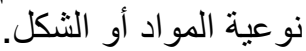

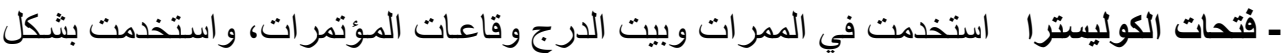

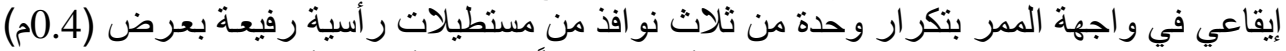

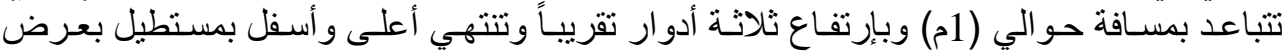

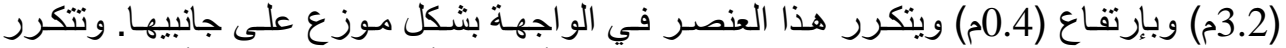

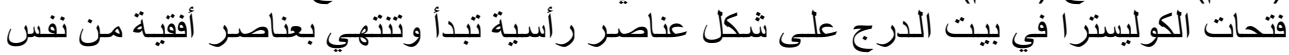

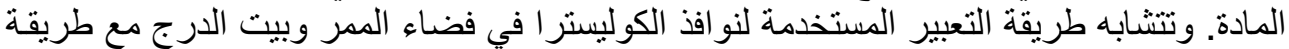

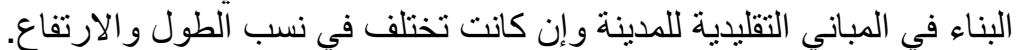

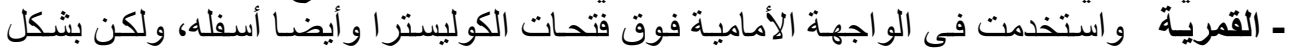

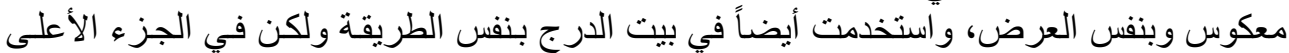

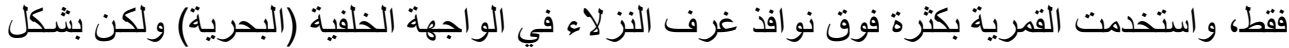

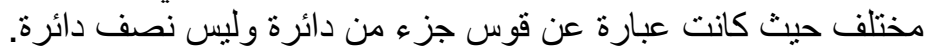

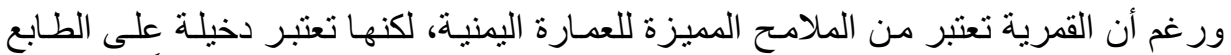

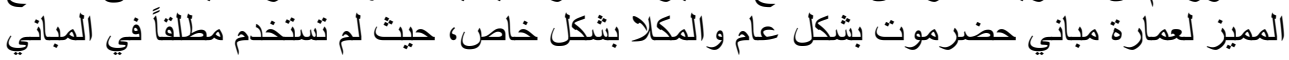
التقليدية بالمدينة.

ـ مواد البناء المستخدمة إستخدم نظام البناء الهيكلي بالخرسانة المسلحة والطوب الأسمنتي في أعمال

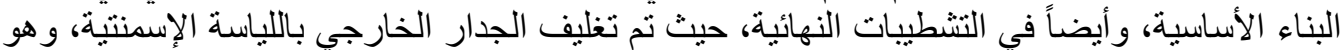

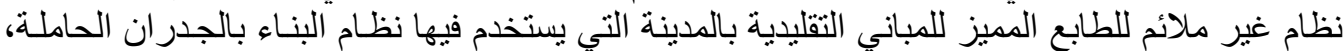

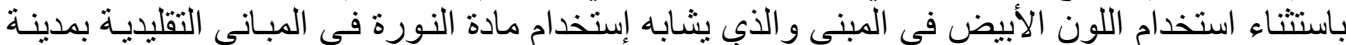

ـ الحليات استخدم نوعين من العقود والأقو اس في الواجهتين الرئيسيتين وهما:

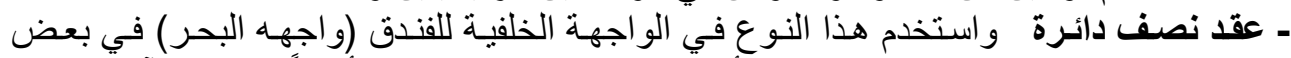

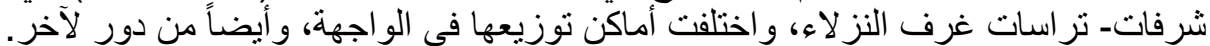

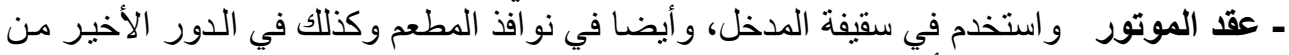
المبنى في الجزء الخاص بأجنحة الفندق. ولقد استخدم هذين النوعين من العقود في المباني التقليدية للمدينة ولو أنها اختلفت في ألتون أماكنها

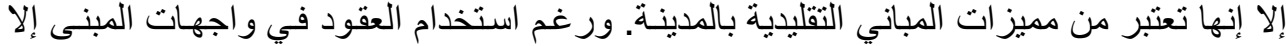
انه تم إهمال أنو اع أخرى من الحليات المستخدمة بالمدينة منل الزخارف الكئة الكورنيش. 


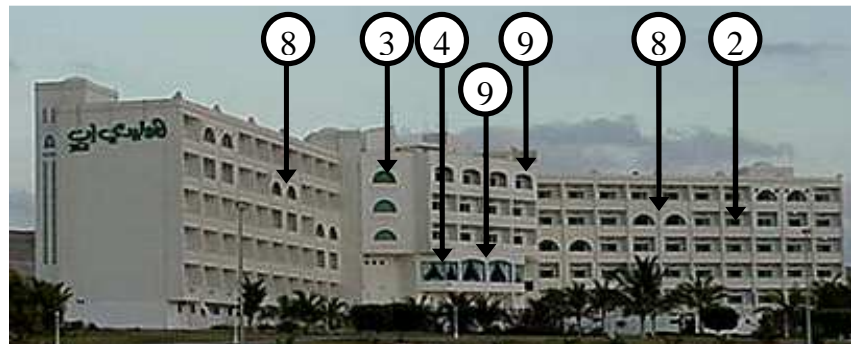

الواجهة الخلفية (البحرية)
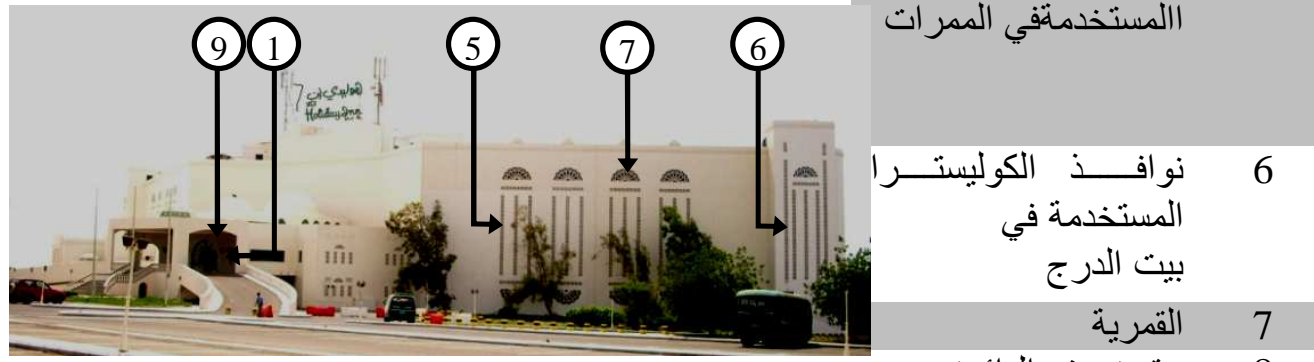

8

9

الواجهة الأمامية

شكل (11) المعالجات المعمارية لفندق هوليدي ان مكلا

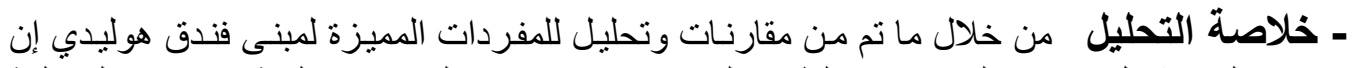

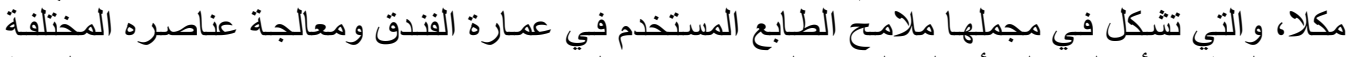

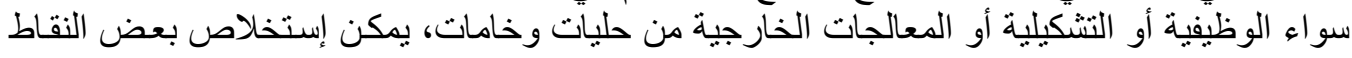

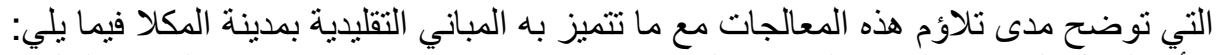

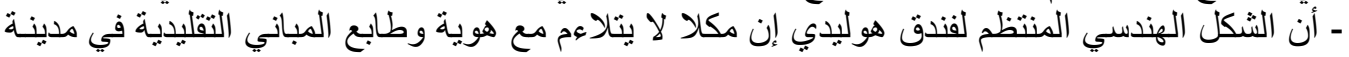

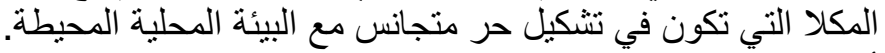

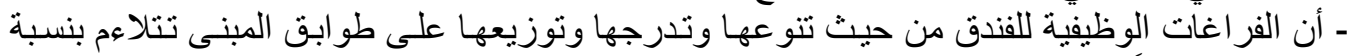

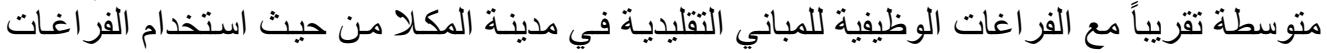

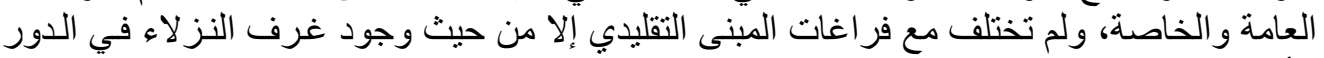

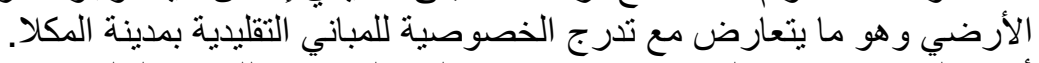

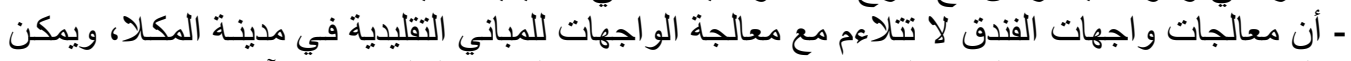

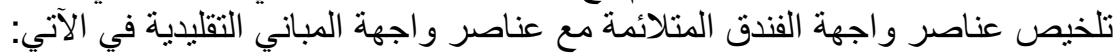

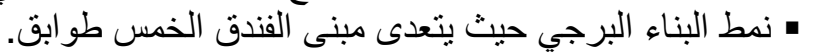

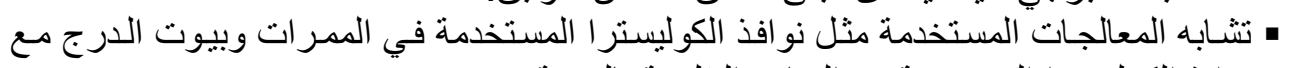
نو افذ الكوليستر ا المستخدمة في المباني التقليدية المباتية بالمدينة.

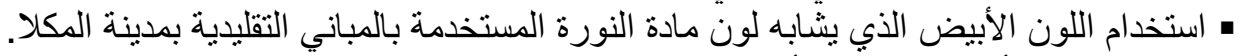

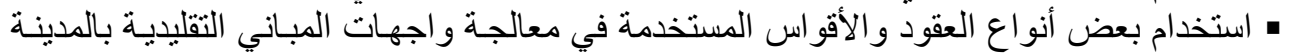

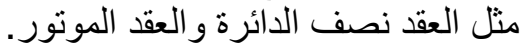

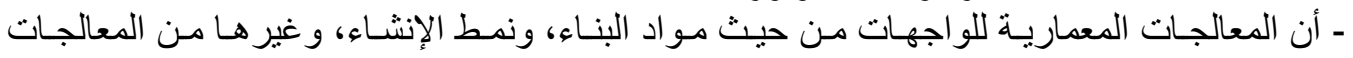

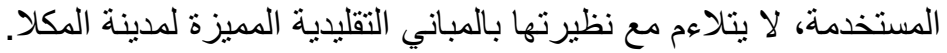


يقع فندق رييون سيتي في المنطقة الوسطى من المدينة في موقع ينوسط أحياءها الرئيسية و على الثـارع الرئيسي الذي يربط بين مدينتي عدن و المكلا، و وهو من الفنادق المصنفة (3ن النجوم).

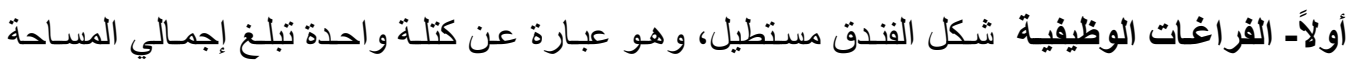

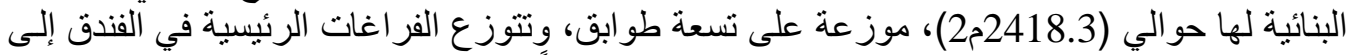

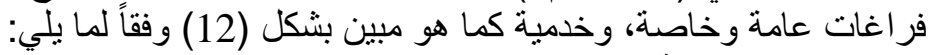

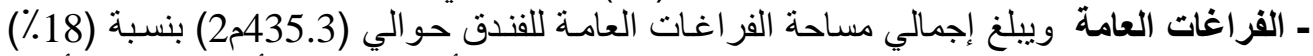

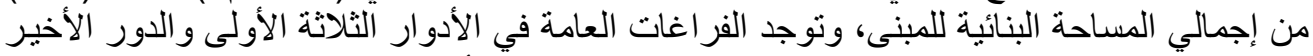

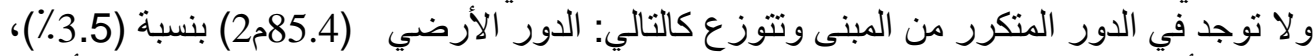

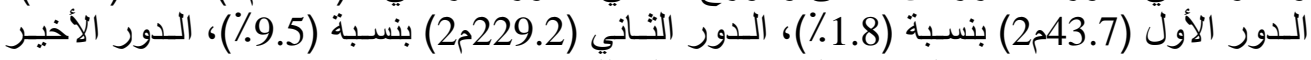

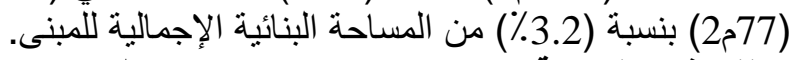

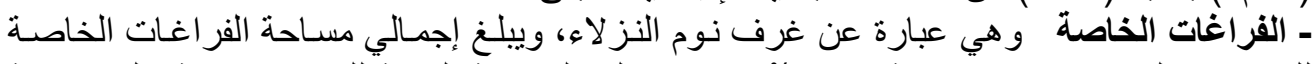

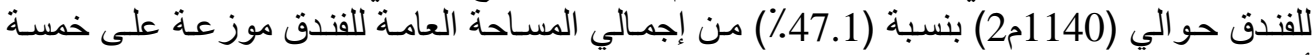

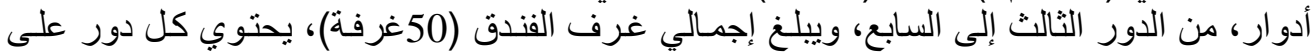
(10غرف) بمساحة إجمالية (228م2) لكل دور بنسبة (9.2\%) من إجمالي المساحة البنائية للفندق.

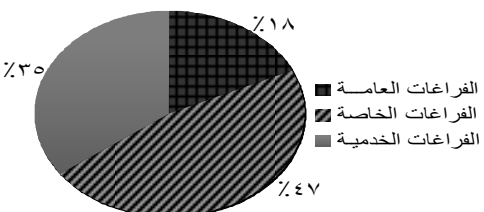

توزيع الفر اغات الوظيفية لفندق ريبون

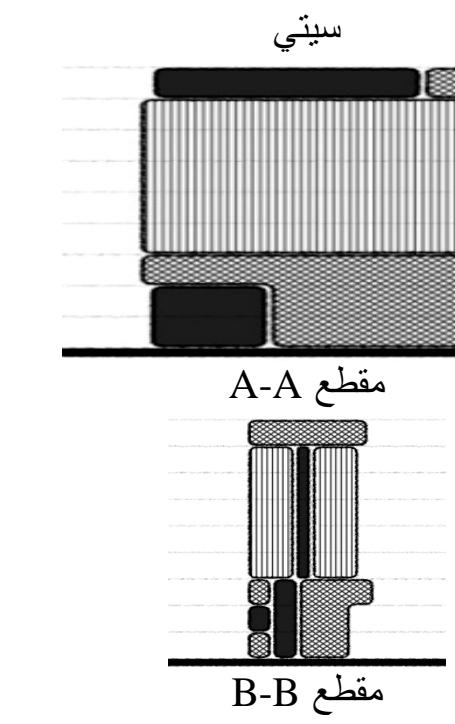

الفر اغات الخدمية (الخدمات وعنا
الفر اغات الوظيفِية للفندق: - الفر

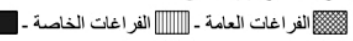
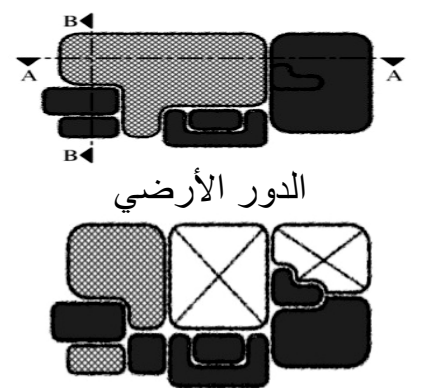

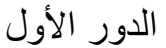

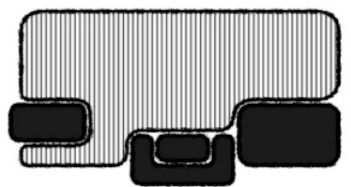

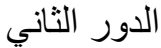

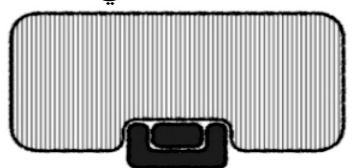

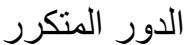

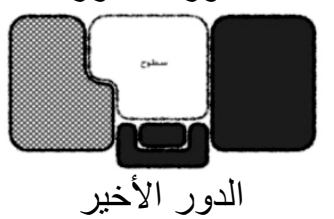

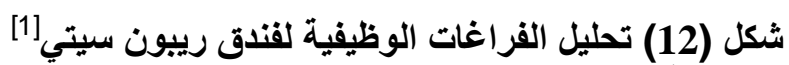

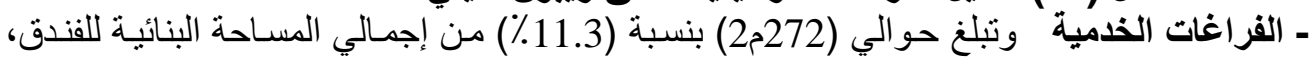

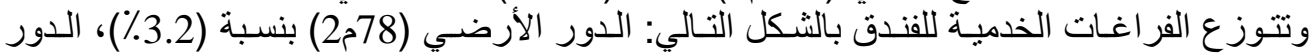


الأول (56م2) بنسبة (2.3\%)، الدور الثاني (36م2) بنسبة (1.5\%)، الدور الأخير (102م2) بنسبة (4.2\%) من المساحة البنائية الإجمالية للمبنى.

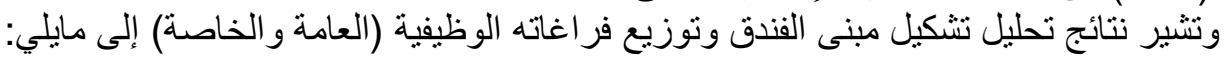

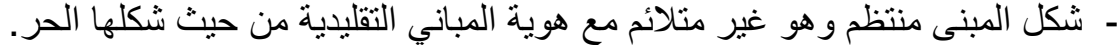

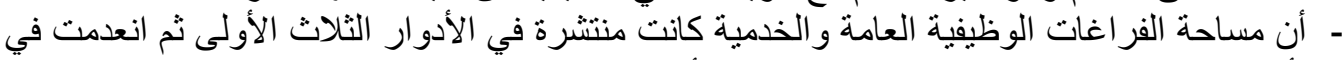

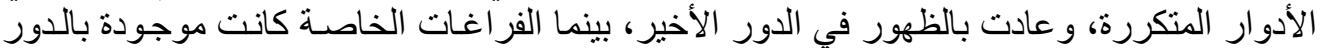

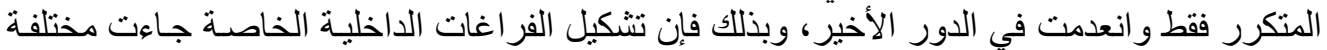
مع ما يتفق من الخصوصية والتدرج التور الأيفي التي تتميز به المباني التقليدية.
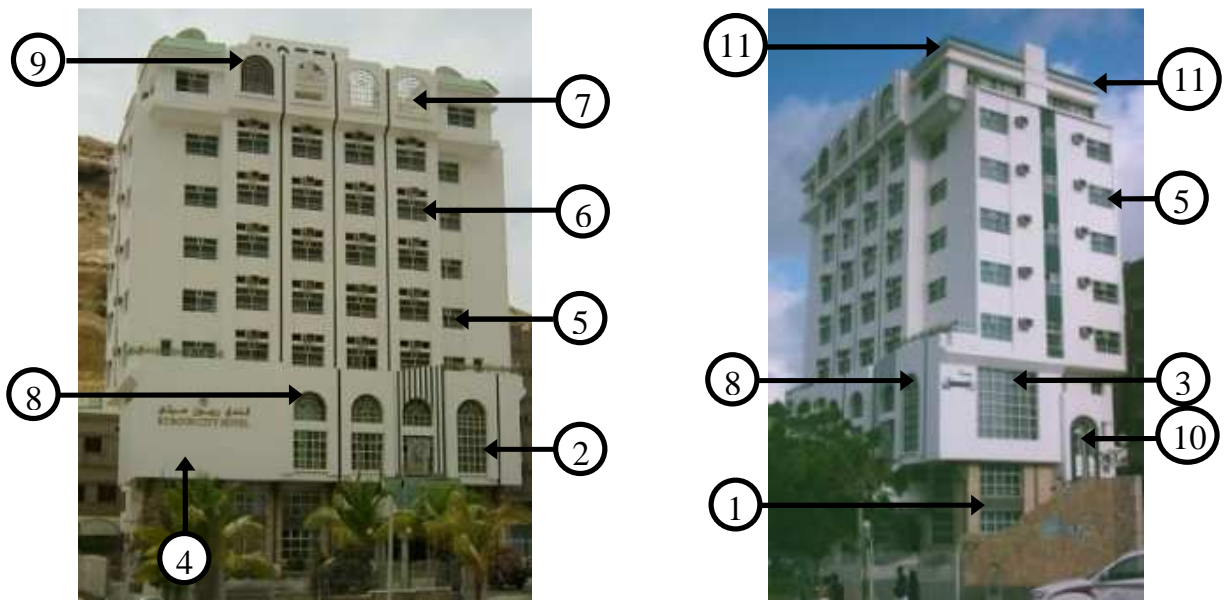

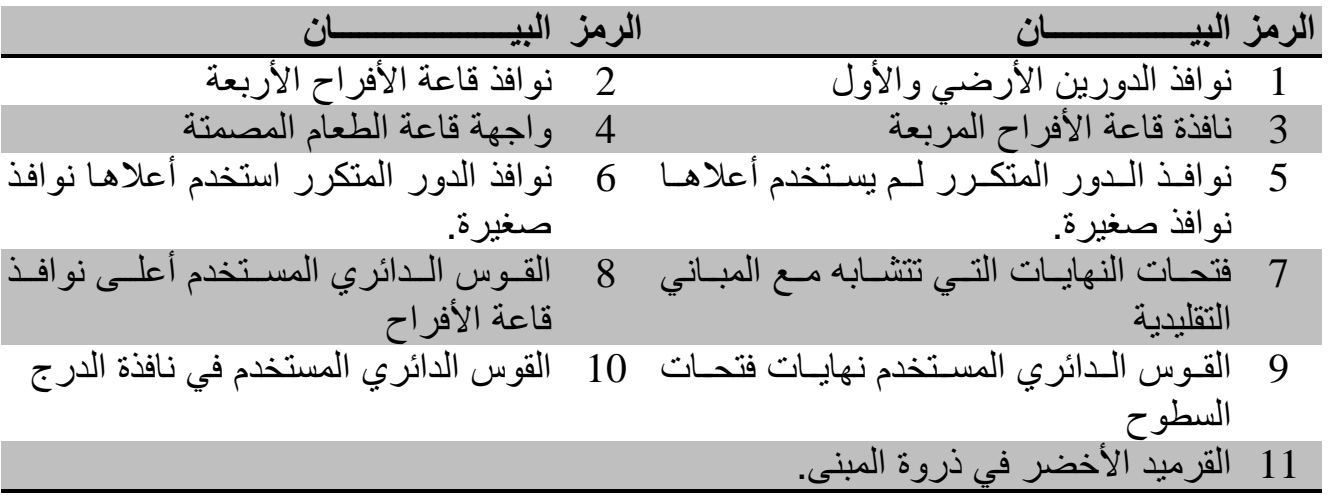

\section{شكل (13) المعالجات المعمارية لفندق ريبون سيتي}

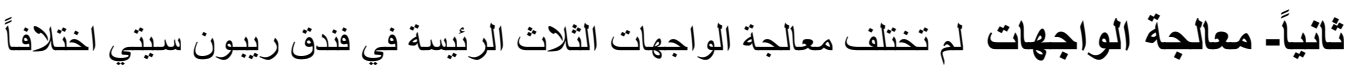

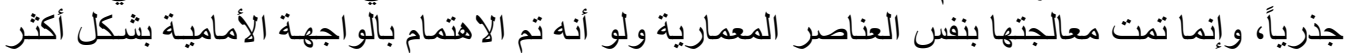

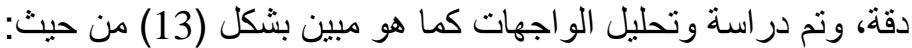

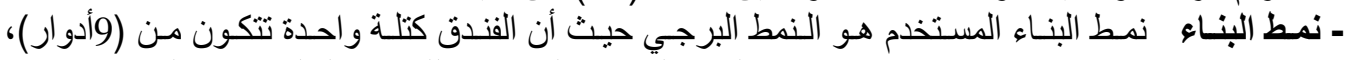
ويتلاءم نمط مبنى فندق رييون سيني مع نمط البناء البرجي المستخدم للمباني التقليدية في المدينة.

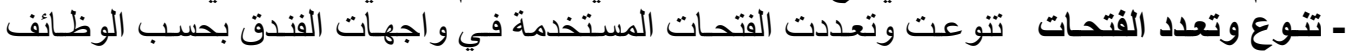

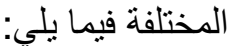




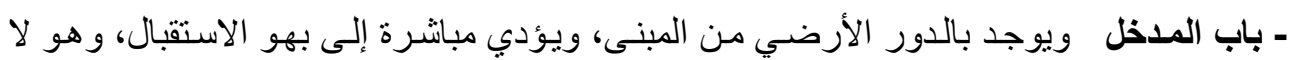

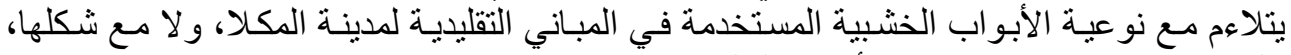
ولهذا فهو لا يتو افق مع نوعية الأبواب التقلية التوابية.

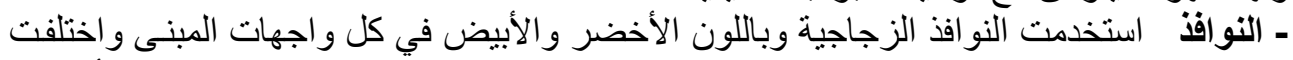

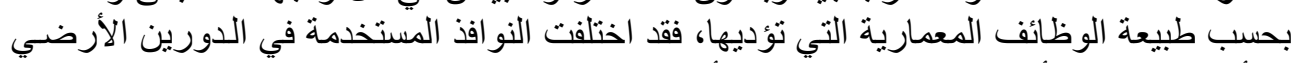

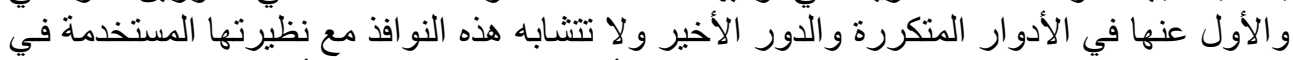

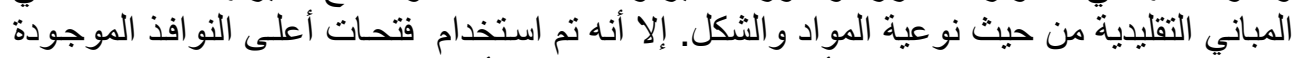

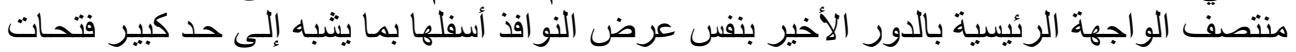
السطوح في المباني التقليدية.

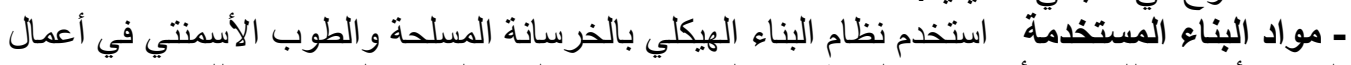

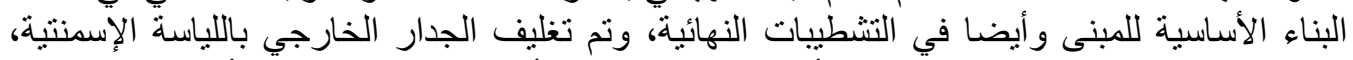

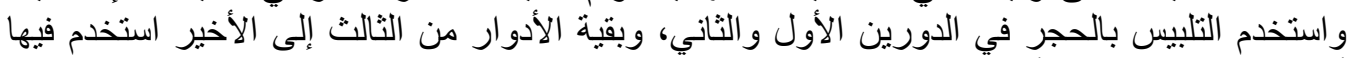

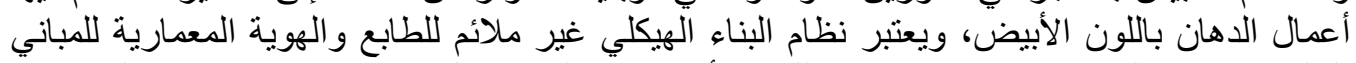

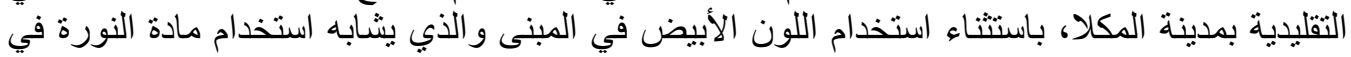
الدهان الخارجي للمباني التقليدية بالمدينة.

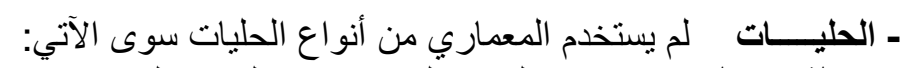

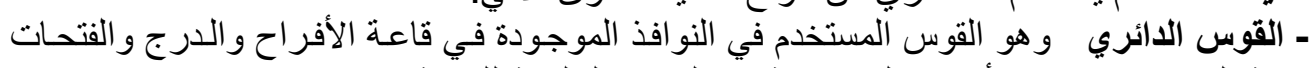

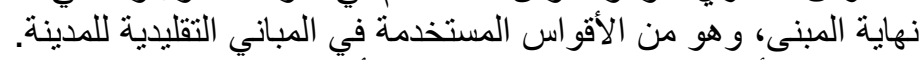

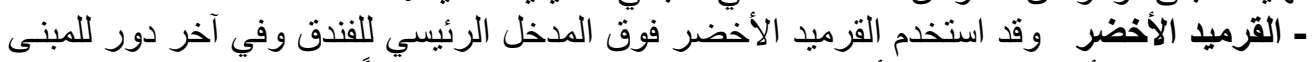

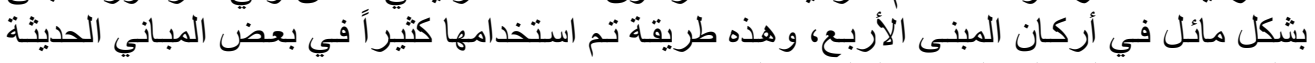

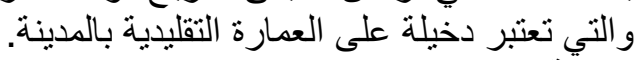

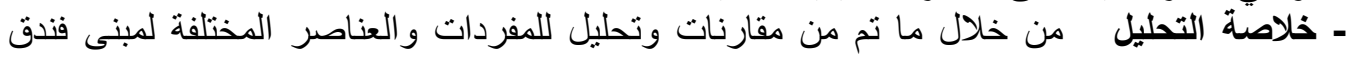

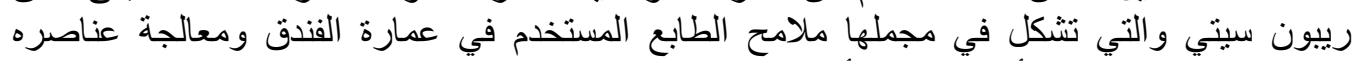

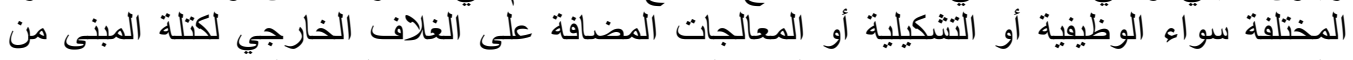

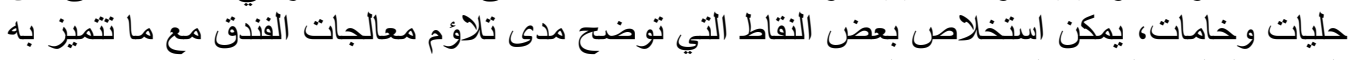

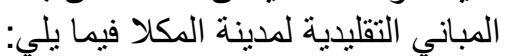

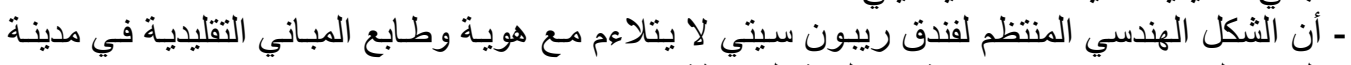

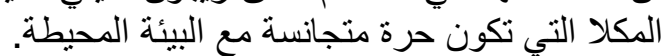

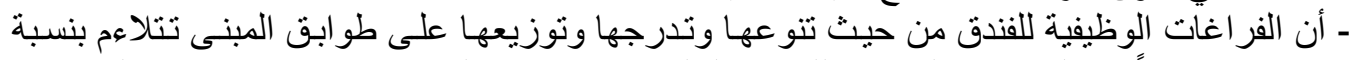

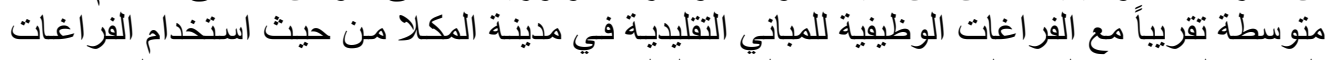

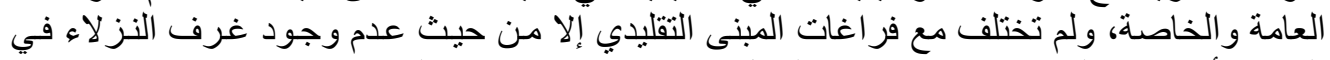

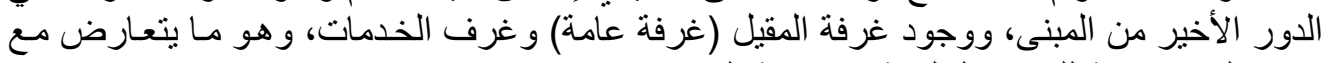
تدرج الخصوصية للمباني التقليدية في مدينة المكلا.

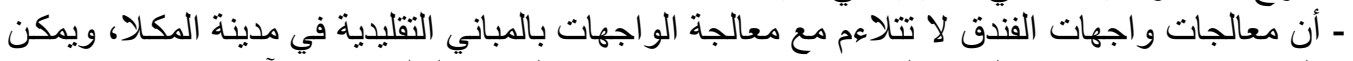

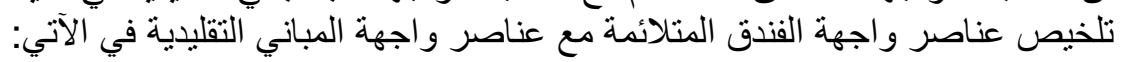

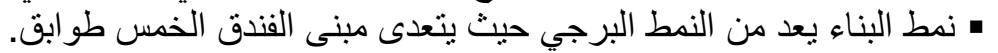

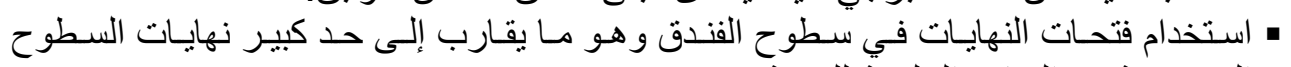
المستخدمة في المباني التقليدية للمدينة.

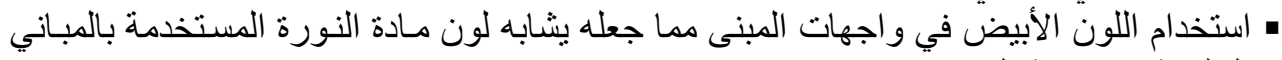
التقليدية في مدينة المكلا. ـ استخدام العقد النصف دائري في بعض أجز اء الو اجهة وبالتحديد في قاعة الأفر اح و الدرج و وهو القوس التي يستخدم في و اجهات المباني التقليدية في المدينة. 


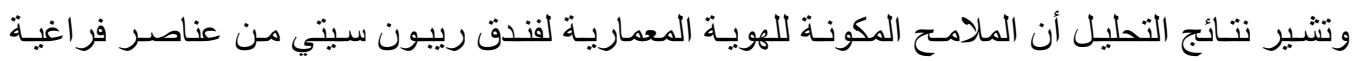

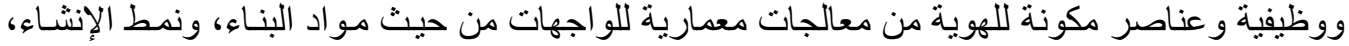
و غير ها من المعالجات المستخدمة، لا يتلاءم مع تصميم المباني التقليدية لمدينة المكلا.

3-2-4 وهو من الفنادق الو اقعة في الضواجي احي الغربية للمدينة في منطقة فوه، وللفندق موقع متميز بالقرب من

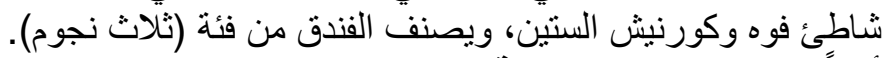

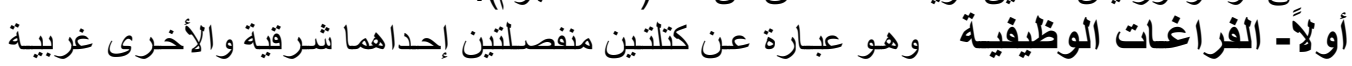

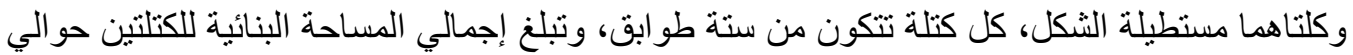

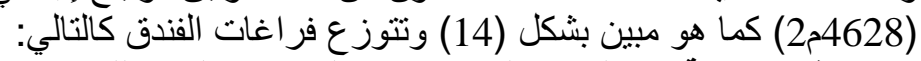

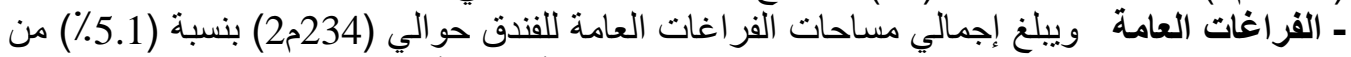

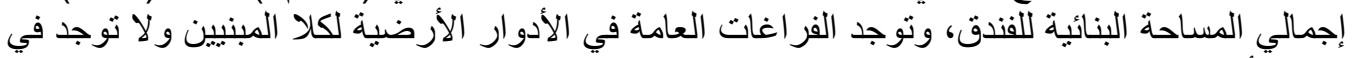

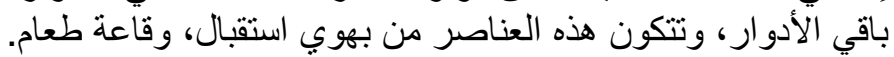

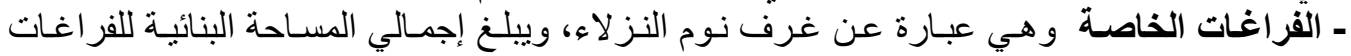

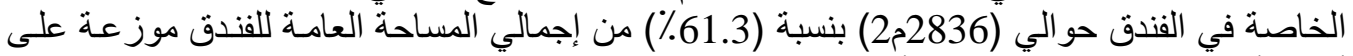

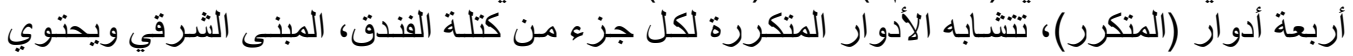

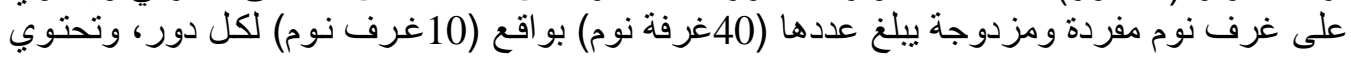

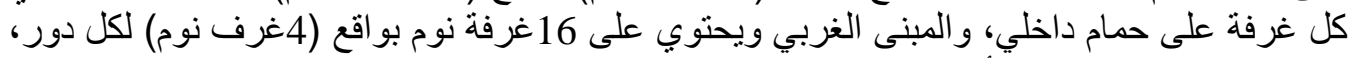
و16جناح موز عة بو اقع (4أجنحة) لكل دور، وكما هو مبين بشئ بشكل (14).

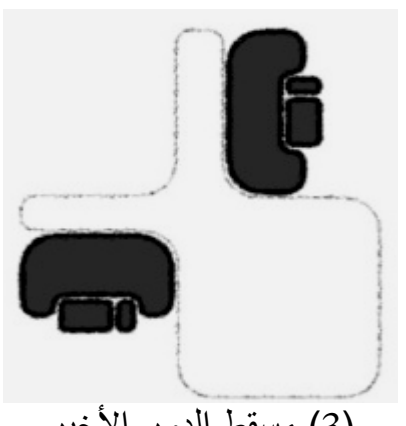

(3) مسقط الدور الأخير

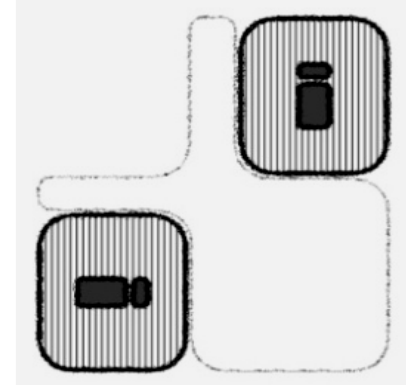

(2) مسقط الدور المتكرر أربعة

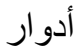

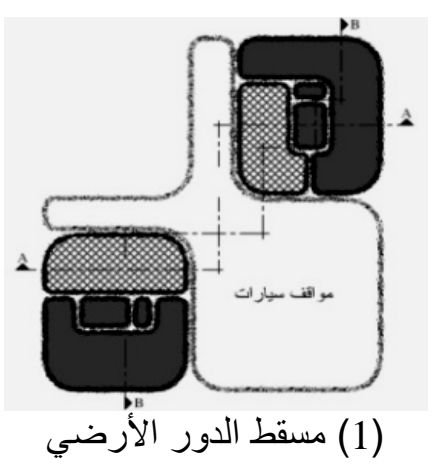

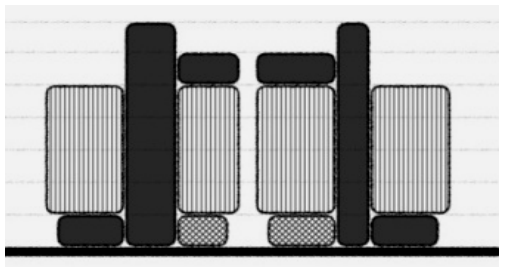

مقطع B-B

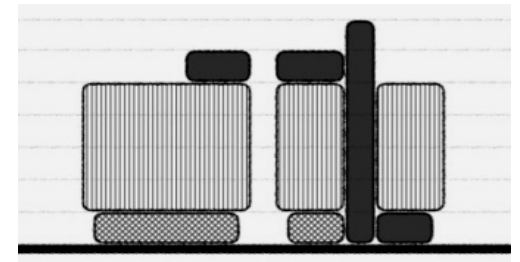

A-A مقطع 

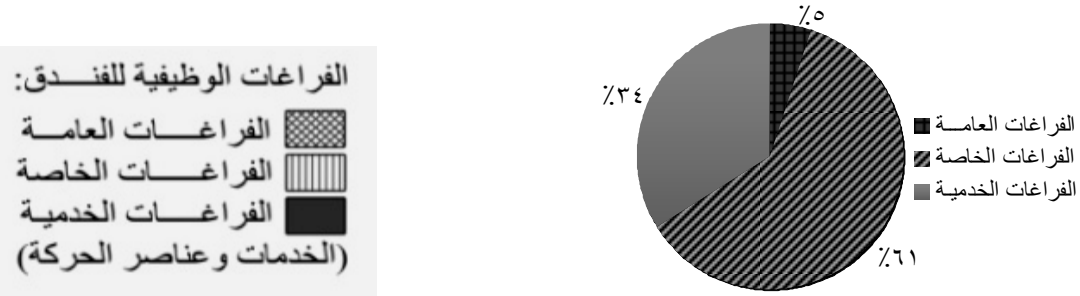

توزيع الفر اغات الوظيفية لفندق الأبر اج

شكل (14) تحليل الفراغات الوظيفية لفندق الأبراج[1]

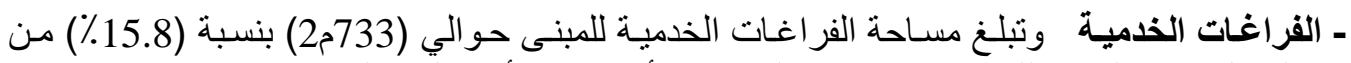

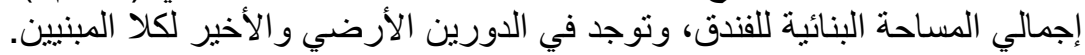

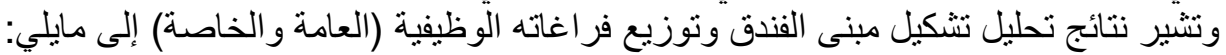

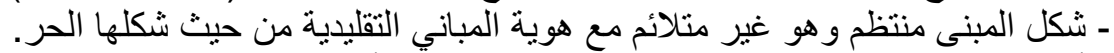

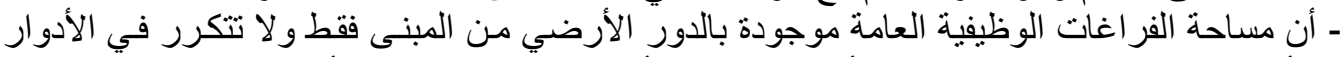

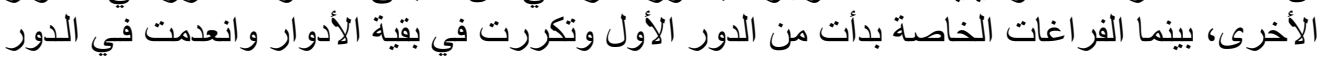

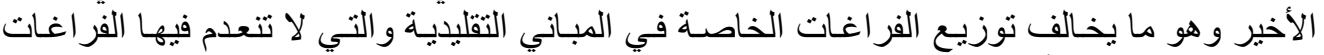

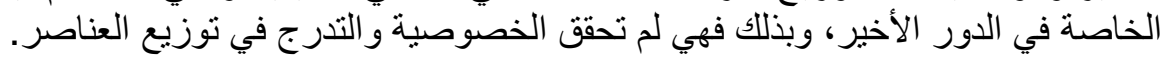

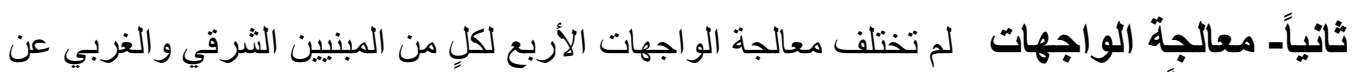

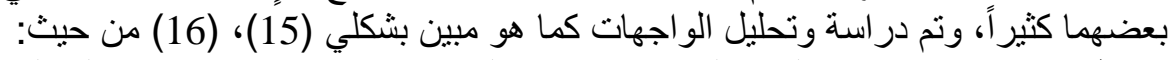

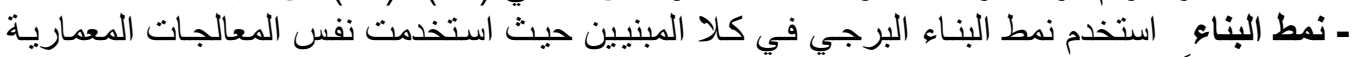

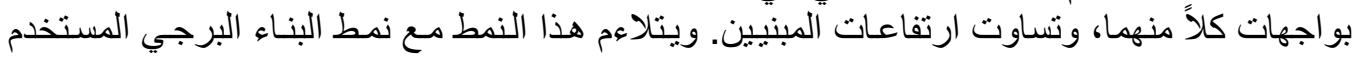
لمباني التقليدية في المدينة.

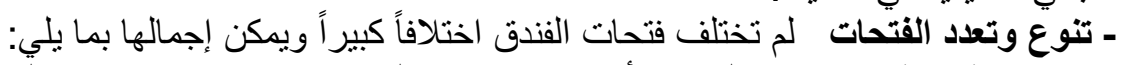

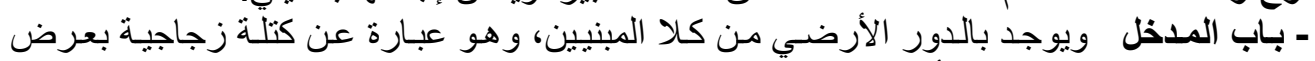

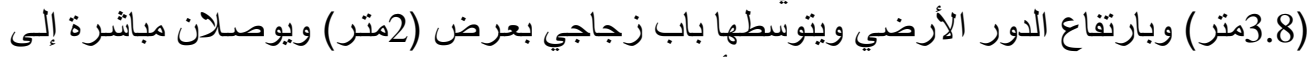

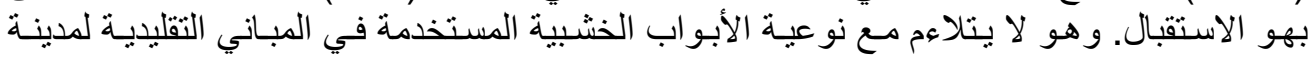

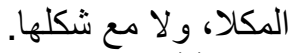

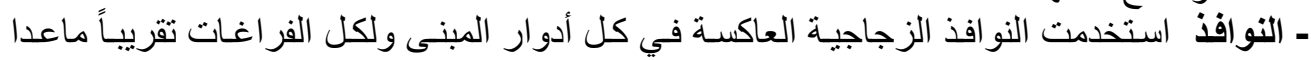

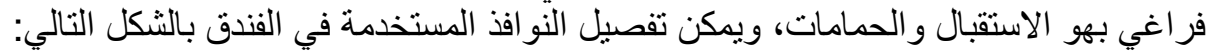

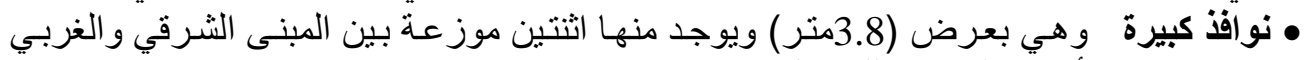
وتقع بجانب الأبو اب الرئيسية للمداخل.

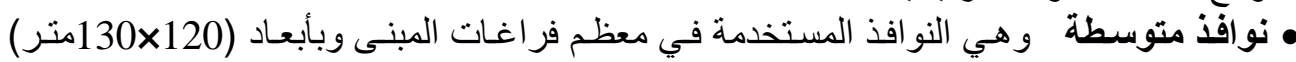

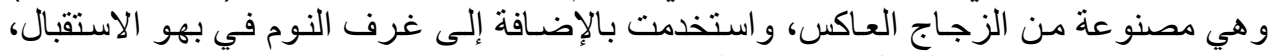

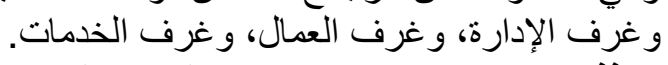

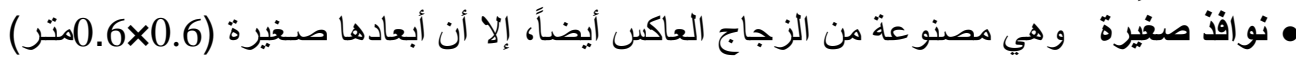

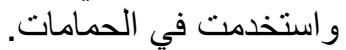

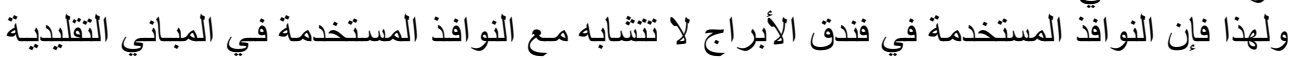
من حيث نوعية المو اد و الثكل، وبذللك فهي لا تتلاءم مع الطابع المميز للمباني التقليدية بالمدينة. 


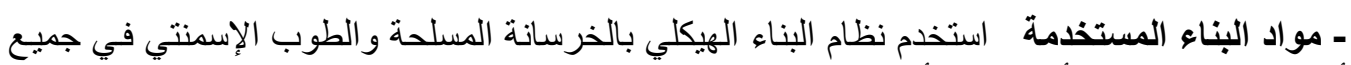

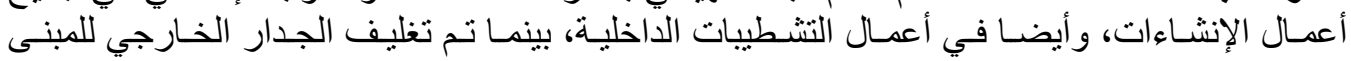

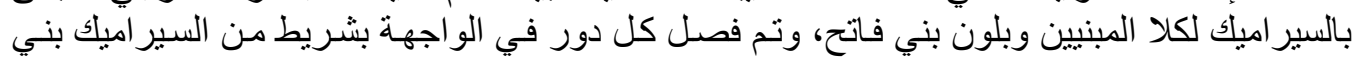

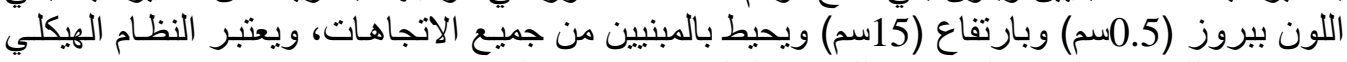

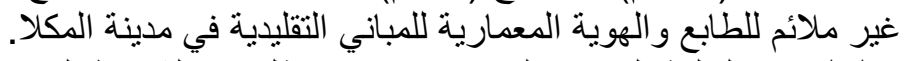

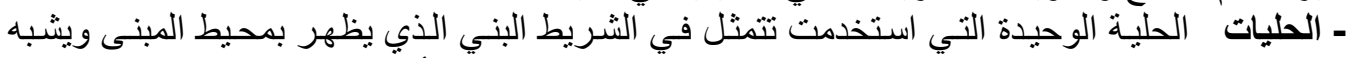

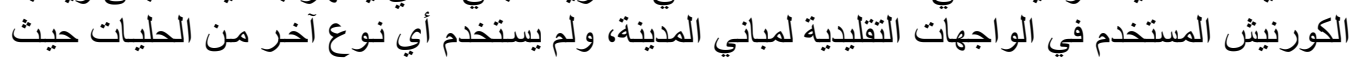

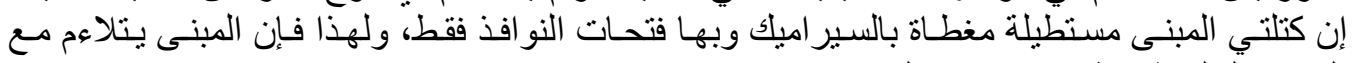

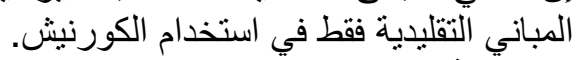

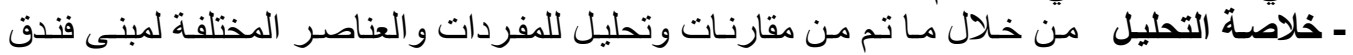

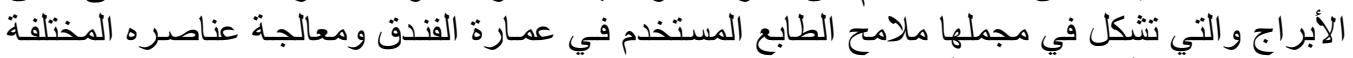

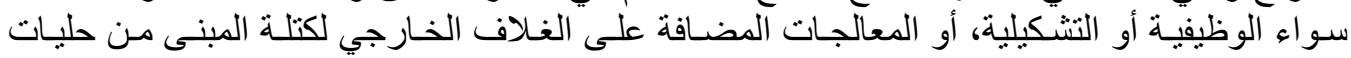

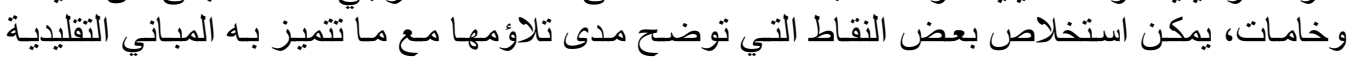
لمدينة المكلا: ـ الثكل الهندسي المنتظم لفندق الأبر اج لا يتلاءم مع هوية وطابع المباني التقليدية في مدينة المكلا التي تكون حرة متفاعلة مع البيئة المحيطة. - الفر اغات الوظيفية للفندق من حيث تلفي الفينة عها وتدرجها وتوزيعها على طو ابق المبنى تتلاءم بنسبة كبيرة

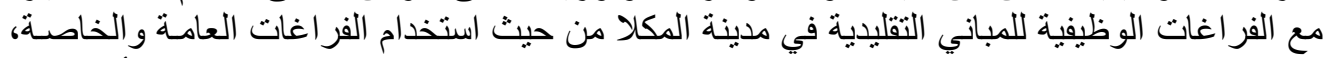

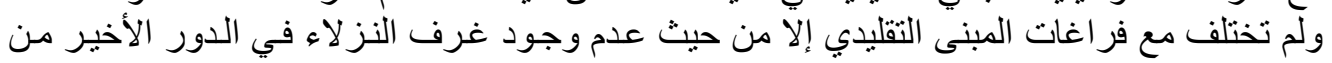

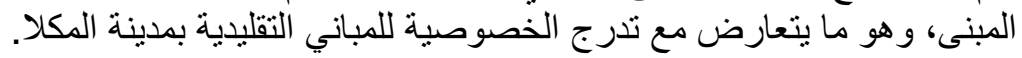

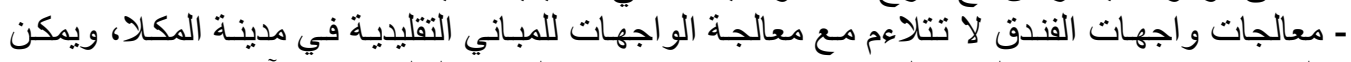

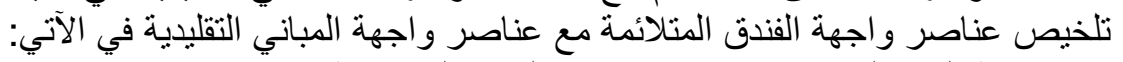

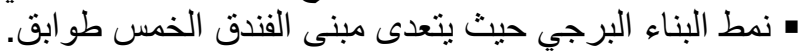

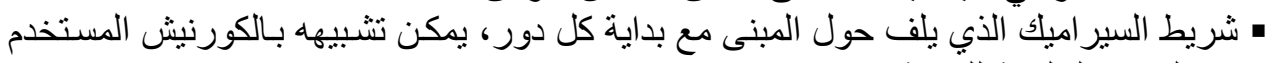
في البيوت التقليدية للمدينة.

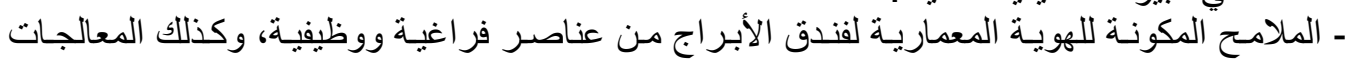

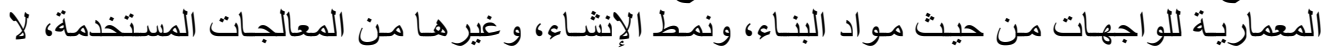

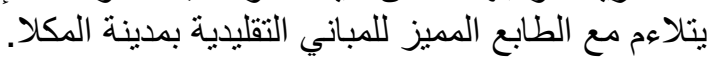

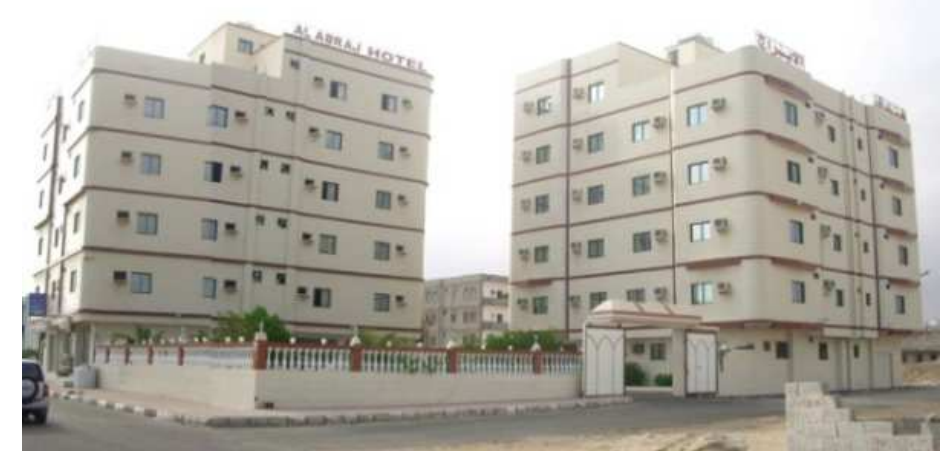

شكل (15) التشكيل الكتلي لقندق الأبراج السياحي* 


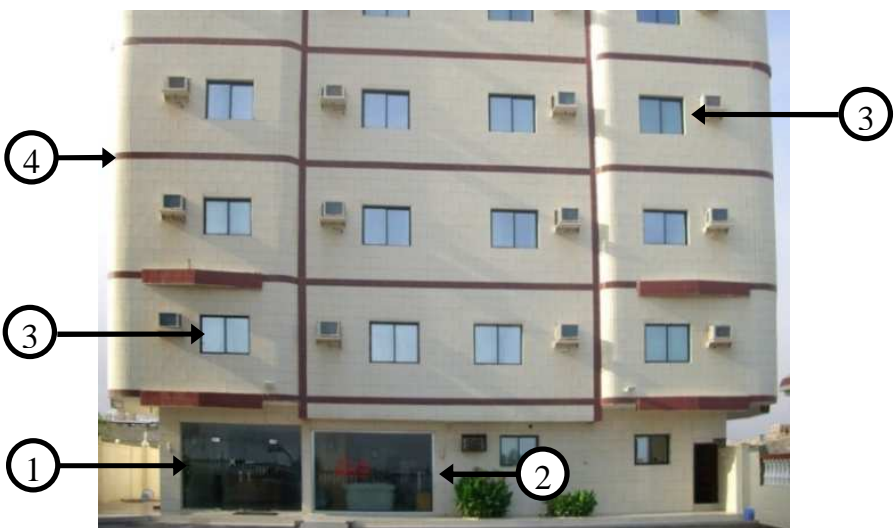

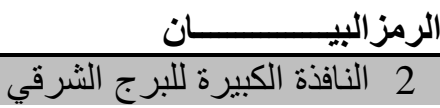

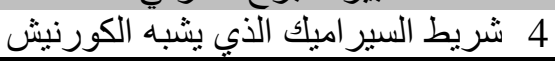

الرمز البيــــــــــــــان 1

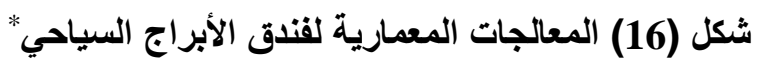
جدول (1) تقييم مباني الفنادق مع هوية المباني التقليدية

\begin{tabular}{|c|c|c|c|c|c|}
\hline الأبراج السياحي & ريبون سيتي & هوليدي ان مكلا & \multicolumn{2}{|c|}{ خصائص العمارة المحلية } & التقييير \\
\hline 0 & 0 & 0 & |بهو الاستقبـــال & \multirow{3}{*}{ (الفر اغتات العامة) } & \multirow{6}{*}{ 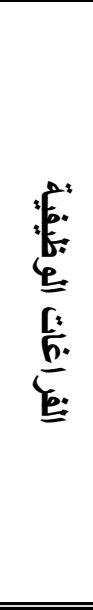 } \\
\hline ○ & $\theta$ & 0 & الصالات & & \\
\hline 0 & 0 & 0 & (الكافتيـريـا) & & \\
\hline$\theta$ & ○ & $\theta$ & النـــــ & 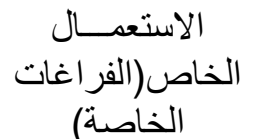 & \\
\hline 0 & ○ & - & (غير ذلكــازن & الفراغــات & \\
\hline$\square$ & 口 & 口 & \multicolumn{2}{|c|}{ شكل المسقــط غير منتظم } & \\
\hline$\theta$ & $\theta$ & $\theta$ & \multicolumn{3}{|c|}{ التقييم النهائي للفر اغات الوظيفية } \\
\hline - & ○ & ○ & \multicolumn{2}{|c|}{ 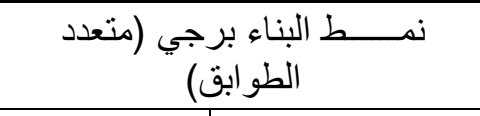 } & \\
\hline$\square$ & $\square$ & $\square$ & المدخـل & \multirow{4}{*}{ تنوع وتعدد } & $\frac{E}{E}$ \\
\hline$\square$ & $\square$ & 0 & 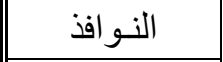 & & $\cdot \dot{E}^{*}$ \\
\hline$\square$ & $\square$ & $\square$ & المشربيات & & \\
\hline$\square$ & $\square$ & $\square$ & المنـاور & & \\
\hline
\end{tabular}




\begin{tabular}{|c|c|c|c|c|}
\hline$\square$ & 0 & 口 & معالجة نهاية & \\
\hline$\square$ & $\theta$ & $\square$ & الأحجـــار & \multirow{4}{*}{ مو اد البنــــــاء } \\
\hline$\square$ & $\square$ & 口 & الطيـن & \\
\hline$\square$ & 0 & 0 & النــورة & \\
\hline$\square$ & $\square$ & $\square$ & بالخشـبــ & \\
\hline$\square$ & $\square$ & 口 & الزخارف & \multirow{3}{*}{ حلبـــات } \\
\hline 0 & $\square$ & 口 & الكورنيش & \\
\hline$\square$ & 0 & 0 & الأقــواس & \\
\hline$\square$ & $\theta$ & $\theta$ & \multicolumn{2}{|c|}{ قييم النهائي لمعالجة الو اجهـات } \\
\hline$\square$ & $\theta$ & $\theta$ & \multicolumn{2}{|c|}{ تلقيبم النهائي لتلاؤم هوية الفنادق } \\
\hline
\end{tabular}

\begin{tabular}{|c|c|c|c|c|c|c|c|}
\hline غير متلائم & \multirow{2}{*}{$\square$} & ضعيف & \multirow{2}{*}{0} & متوسط & \multirow{2}{*}{$\theta$} & جيا & \multirow[t]{2}{*}{8} \\
\hline 0 & & $\% 40>$ & & $\% 40-70$ & & $\% 70<$ & \\
\hline
\end{tabular}

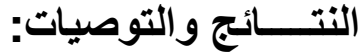

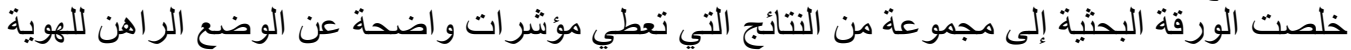

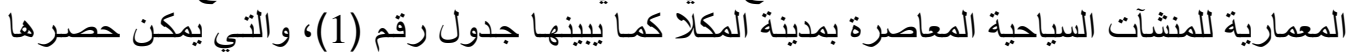

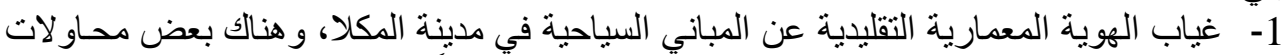

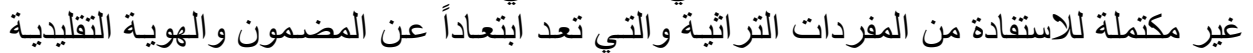
المميزة للعمارة المحلية للمدينة.

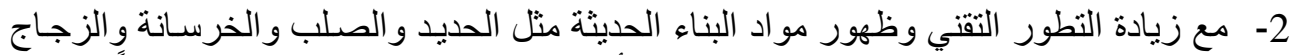

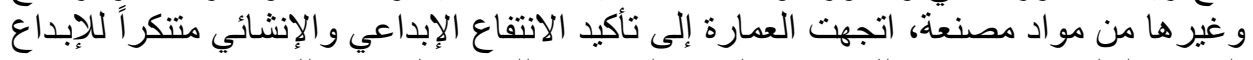

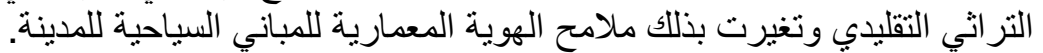

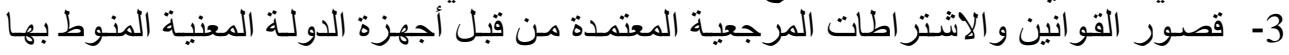

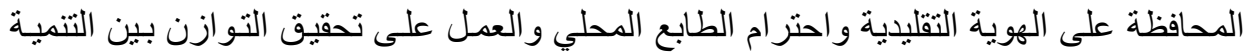

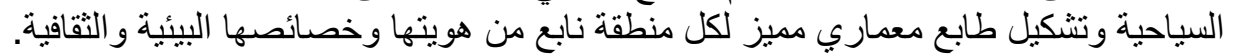

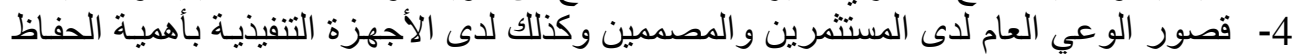

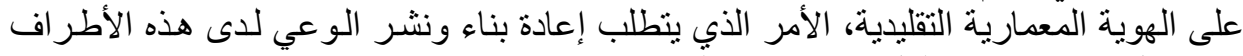
من خلال بر امج خاصة لكل فئة من هذه الفئات.

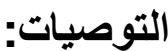

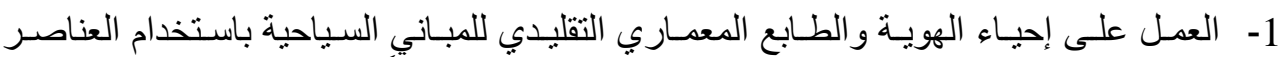

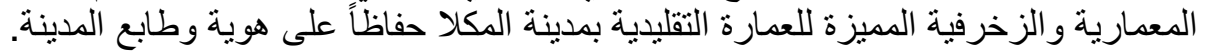

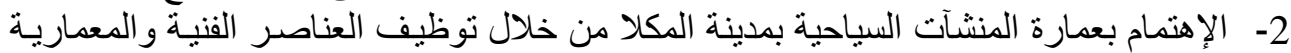
و الثقافية الحضرمية وخلق طابع مميز لها معبرة عن طابع البيئة المحيطة. 


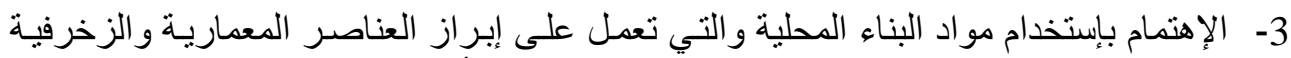

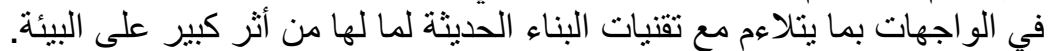

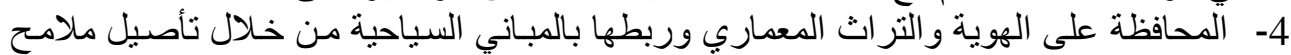

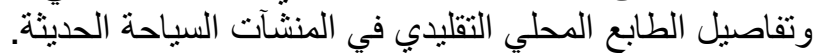

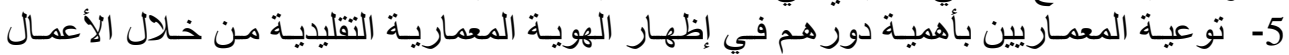

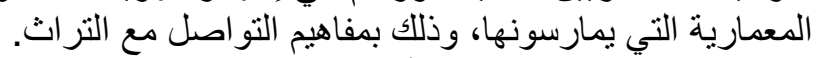

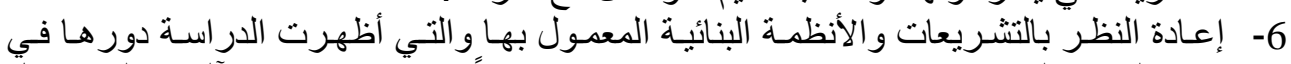

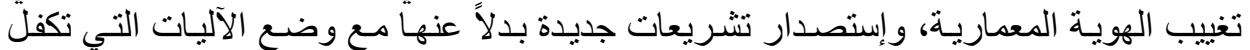

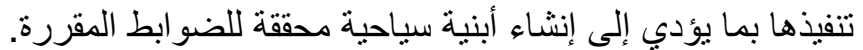

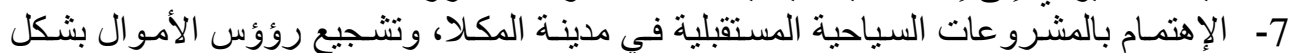

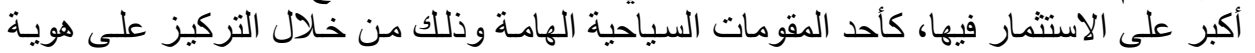

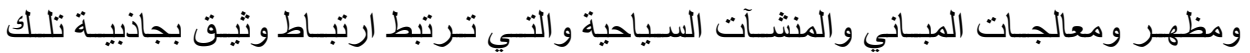
المشرو عات للسائحين و الزائرين المحليين و العالمبين.

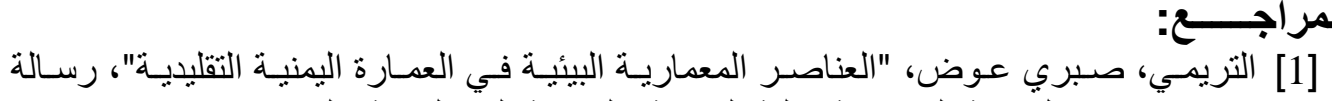

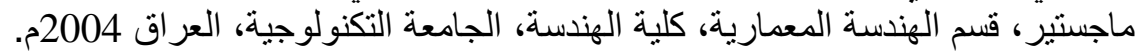

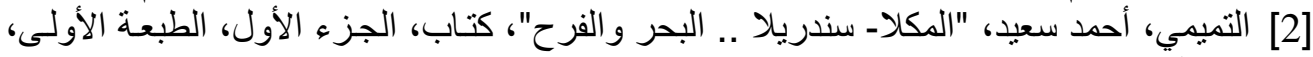

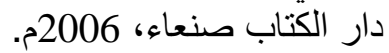
[3] الخضر، سالم عمر، بن بدر، عبده عبداله ، "المكلا عروس البحر الحضـرمية"، مركز عبادي

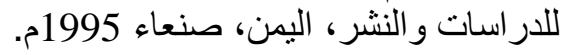

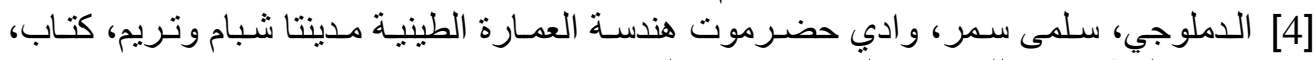

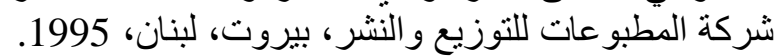

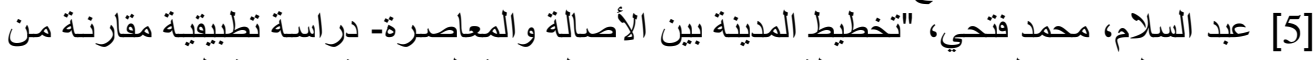

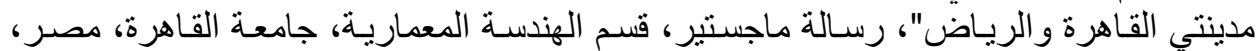
1995م. مدين [6] [6مل الباحثين عن مركز تطوير الموانئ اليمينة. [7] زيار ات ميدانية للباحثين.

[8] Damluji, Salma Samar: "The Architecture of Yemen", Laurence King Publishing, London, UK, 2007

[9] http://www.yemen-nic.info/gover (موقع المركز الوطني للمعلومات- اليمن). 